\title{
Depletion of cardiolipin induces major changes in energy metabolism in
} Trypanosoma brucei bloodstream forms

Mauro Serricchioํ, Carolina Hierro-Yap ${ }^{2}$, David Schädeli ${ }^{1,3}$, Hisham Ben Hamidane ${ }^{4}$, Andrew Hemphill ${ }^{5}$, Johannes Graumann ${ }^{4, *}$, Alena Zíková ${ }^{2,6, \#}$ and Peter Bütikofer ${ }^{1, \#}$ (1)

${ }^{1}$ Institute of Biochemistry and Molecular Medicine, University of Bern, Bern, Switzerland

${ }^{2}$ Faculty of Science, University of South Bohemia, Ceske Budejovice, Czech

Republic.

${ }^{3}$ Graduate School for Cellular and Biomedical Sciences, University of Bern, Bern,

Switzerland

\section{${ }^{4}$ Weill Cornell Medicine - Qatar, Doha, State of Qatar}

${ }^{5}$ Institute of Parasitology, Vetsuisse Faculty, University of Bern, Bern, Switzerland

${ }^{6}$ Institute of Parasitology, Biology Centre, Czech Academy of Sciences, Ceske Budejovice, Czech Republic.

${ }^{*}$ Current address: Biomolecular Mass Spectrometry, Max Planck Institute for Heart and Lung Research, Bad Nauheim, Germany

\#Correspondence to:

Alena Zíková, Ph.D., Institute of Parasitology, Biology Centre, Czech Academy of

Sciences, Ceske Budejovice, Czech Republic

E-mail: azikova@paru.cas.cz

or

Peter Bütikofer, Ph.D., Institute of Biochemistry and Molecular Medicine, University of Bern, Bühlstrasse 28, 3012 Bern, Switzerland

E-mail: peter.buetikofer@ibmm.unibe.ch 
2 Running title: Cardiolipin-dependent changes in energy metabolism

3 Keywords: Mitochondria, cardiolipin, electron transport chain, protein complexes,

4 trypanosomes, ATP synthase 


\section{Abstract}

3 Cardiolipin $(\mathrm{CL})$ is a mitochondrial inner membrane glycerophospholipid that 4 associates with mitochondrial proteins to promote their activities and to facilitate protein complex and super-complex formation. Loss of CL leads to destabilized respiratory complexes and mitochondrial dysfunction. The role of $\mathrm{CL}$ in an organism lacking a conventional electron transport chain (ETC) has not been elucidated so far. We now report that in Trypanosoma brucei bloodstream forms, in which the ETC is truncated and composed of alternative oxidase and glycerol-3-phosphate dehydrogenase, and the mitochondrial membrane potential is generated by the

11 hydrolytic action of the $\mathrm{F}_{\mathrm{o}} \mathrm{F}_{1}$-ATP synthase, the inducible depletion of cardiolipin 12 synthase (TbCls) is essential for parasite survival. Loss of TbCls and CL caused a 13 rapid drop in ATP levels and a decline in the mitochondrial membrane potential. 14 Unbiased proteomic analyses revealed a reduction in the levels of many 15 mitochondrial proteins, most notably of $F_{0} F_{1}-A T P$ synthase subunits and of the 16 alternative oxidase, resulting in a strong decline of glycerol-3-phosphate-stimulated 17 oxygen consumption. Interestingly, the changes in cellular respiration preceded the observed decrease in $\mathrm{F}_{0} \mathrm{~F}_{1}$-ATPase stability, suggesting that the truncated ETC is the first pathway responding to the decline in $\mathrm{CL}$. In addition, proteomic and metabolomic analyses revealed that select proteins and pathways involved in glucose and amino

21 acid transport and metabolism are up-regulated during CL depletion, possibly as a 22 stress response to restore cellular ATP levels. 
1 Introduction

Cardiolipin (CL) is a mitochondrial and bacterial glycerophospholipid consisting of four fatty acyl chains and two phosphate groups. Owing to its structure, CL has biophysical properties that set it apart from other glycerophospholipids (reviewed by (Schlame \& Ren, 2009)). CL adopts a hexagonal phase and thus localizes preferentially to sites with high membrane curvature, such as bacterial septa and poles (Mileykovskaya \& Dowhan, 2000; Renner \& Weibel, 2011), and it self-organizes in negatively curved membranes (Beltran-Heredia et al., 2019) found at cristae junctions (Friedman, Mourier, Yamada, McCaffery, \& Nunnari, 2015) and cristae tips (Acehan et al., 2011). CL tightly associates with respiratory complexes (Fiedorczuk et al., 2016; Lange, Nett, Trumpower, \& Hunte, 2001; Shinzawa-Itoh et al., 2007; Solmaz \& Hunte, 2008) and is required for the assembly and stability of super-complexes (Mileykovskaya \& Dowhan, 2014) and the oligomerization of ATP synthase (Acehan, et al., 2011). In addition, several mitochondrial carriers have been shown to interact with CL (Claypool, 2009; Klingenberg, 2009). Finally, CL promotes mitochondrial membrane fusion (Joshi, Thompson, Fei, Huttemann, \& Greenberg, 2012), iron-sulfur cluster biogenesis (Patil, Fox, Gohil, Winge, \& Greenberg, 2013) and induction of apoptosis (Santucci, Sinibaldi, Cozza, Polticelli, \& Fiorucci, 2019).

More recently, depletion of CL has been shown to affect a cell's energy metabolism. In a Saccharomyces cerevisiae mutant lacking CL, due to deletion of the crd1 gene encoding CL synthase, production of acetyl-CoA was decreased as a result of a defect in the pyruvate dehydrogenase bypass pathway (Li et al., 2019). This, together with the observation that $\mathrm{CL}$ is required for the proper function of the iron-sulfur-containing enzymes aconitase and succinate dehydrogenase (Patil, et al., 2013), demonstrated that the tricarboxylic acid (TCA) cycle is impaired in CLdeficient yeast. As a result, in this crd1 $1 \Delta$ mutant anaplerotic pathways are activated to restore acetyl-CoA and TCA cycle intermediates (Raja et al., 2019).

Interestingly, aberrant intermediary metabolism is also a hallmark of Barth syndrome, a human disease caused by mutations in the CL-remodeling enzyme, tafazzin (Schlame \& Ren, 2006). Analyses of plasma metabolites point to alterations in carbohydrate and amino acid metabolism in Barth syndrome patients compared to 32 healthy controls (Cade et al., 2013). Remarkably, perturbations in energy metabolism, in particular in the levels of TCA intermediates and amino acid metabolites, were recently also found in a tafazzin knock out mouse cell line (Raja \& 
1 Greenberg, 2014), linking CL to energy metabolism. Surprisingly, despite these 2 important functions, CL is dispensable for viability in Escherichia coli, S. cerevisiae and mammalian cell lines (Jiang, Gu, Granger, \& Greenberg, 1999; Nishijima et al., 1988; Raemy et al., 2016). In contrast, CL is essential for survival of Trypanosoma brucei procyclic forms in culture (Serricchio \& Bütikofer, 2012).

The biosynthesis of CL occurs on the matrix side of the inner mitochondrial membrane in four steps via the intermediates phosphatidic acid, CDP-diacylglycerol, phosphatidylglycerophosphate and phosphatidylglycerol (PG). In the final step, in most eukaryotes $\mathrm{CL}$ is formed from PG and CDP-diacylglycerol by eukaryotic-type CL synthases. In contrast, in certain parasitic protozoa and prokaryotes, CL is formed from two PG molecules (or from one PG and one phosphatidylethanolamine molecule) by prokaryotic-type CL synthases (Schlame, 2008). Most previous studies aiming to investigate the importance of $\mathrm{CL}$ for inner mitochondrial membrane protein complexes and mitochondrial function were carried out in cells after knocking out key enzymes in the CL biosynthetic pathway. While this approach has yielded a wealth of information on steady-state changes in mitochondrial protein levels and mitochondrial function, such systems are not suited to detect subtle changes and adaptations that occur during $\mathrm{CL}$ depletion. In $T$. brucei procyclic form $\mathrm{CL}$ synthase (TbCls) conditional knock-out parasites, we have recently shown that gradual CL depletion not only affected the stability of mitochondrial respiratory complexes but also decreased the levels of several mitochondrial proteins that have not been previously linked to CL (Schädeli et al., 2019). These proteins, named CL-dependent proteins (CLDPs), were identified by comparing the proteomes of procyclic form trypanosomes at different time-points after induction of $\mathrm{CL}$ depletion using an unbiased mass spectrometry-based approach (Schädeli, et al., 2019).

T. brucei parasites cycle between the fly host, Glossina spp., and mammals, and are the causative agents of human African trypanosomiasis and nagana in domestic animals. To cope with the fundamentally different host environments during its life cycle, the parasite has adapted its energy metabolism to the availability of different nutrients. In the tsetse fly midgut, T. brucei procyclic forms thrive mostly on amino acids, express functional TCA cycle enzymes and generate ATP by substratelevel and oxidative phosphorylation (Hannaert, Bringaud, Opperdoes, \& Michels, 33 2003). In contrast, bloodstream form parasites produce cellular ATP via cytosolic 
1 substrate-level phosphorylation by aerobic glycolysis. As a result of the constant 2 availability of glucose in the blood, bloodstream form trypanosomes minimize 3 mitochondrial energy metabolism and down-regulate key enzymes of the TCA cycle 4 as well as the cytochrome c-containing respiratory chain protein complexes (Zíková, 5 Hampl, Paris, Tyc, \& Lukes, 2016). In the absence of the proton-pumping complexes 6 III and IV, the electrochemical potential across the inner mitochondrial membrane in $7 \quad T$. brucei bloodstream forms is generated and maintained by the hydrolytic activity of 8 the $F_{0} F_{1}-A T P$ synthase (Nolan \& Voorheis, 1992; Schnaufer, Clark-Walker, 9 Steinberg, \& Stuart, 2005). As a result, the mitochondrion differs morphologically and 10 metabolically between these life cycle stages (Priest \& Hajduk, 1994; Smith, 11 Bringaud, Nolan, \& Figueiredo, 2017; Tielens \& van Hellemond, 2009; Vickerman, 1985; Zíková, Verner, Nenarokova, Michels, \& Lukes, 2017).

In the present study, we have exploited the unusual role of the T. brucei bloodstream form mitochondrion to study the effects of CL depletion in a cell lacking

15 a canonical respiratory chain and an $\mathrm{F}_{0} \mathrm{~F}_{1}$-ATP synthase working in reverse direction compared to most other eukaryotes. We generated bloodstream form TbCls conditional knock-out parasites and examined time-dependent changes in protein levels and metabolites during $\mathrm{CL}$ depletion using quantitative comparative mass spectrometry. Our results show that ablation of $\mathrm{TbCls}$ expression causes a decreased respiration rate and rapid drop in cellular ATP levels resulting in a reduction of the mitochondrial membrane potential $(\Delta \Psi \mathrm{m})$. Proteomic and metabolomic analyses revealed a large number of proteins that were down-regulated during CL depletion and, unexpectedly, a set of mitochondrial proteins involved in energy metabolism that were up-regulated, possibly to counteract the loss of ATP and $\Delta \Psi \mathrm{m}$. 


\section{$1 \quad$ Results}

2 Generation and characterization of bloodstream form conditional TbCls knock3 out parasites

To study the importance of $\mathrm{CL}$ in an organism lacking a canonical cytochrome $c$-containing electron transport chain (ETC), we generated $T$. brucei bloodstream form TbCls conditional knock-out ( $\mathrm{TbCls} \mathrm{KO}$ ) mutants by deleting both endogenous $\mathrm{TbCls}$ genes and expressing a tetracycline-dependent HA-tagged ectopic copy of TbCls (Fig. 1A). Replacement of both TbCls alleles in the conditional TbCls knock-out mutant was confirmed by Southern blotting (Fig. S1A) and the presence and correct genomic integration of the two antibiotic resistance genes was verified by PCR using gene-specific primers (Fig. S1B). Removal of tetracycline from the culture medium for $24 \mathrm{~h}$ resulted in a reduction of TbCls mRNA (Fig. 1B), disappearance of HA-tagged TbCls (Fig. 1C) and growth arrest after $48 \mathrm{~h}$ followed by parasite death (Fig. 1D), demonstrating that expression of $\mathrm{TbCls}$ is essential in $T$. brucei bloodstream forms and that growth of parasites can be maintained by expressing a tetracycline-dependent HA-tagged copy of TbCls. De novo production of $\mathrm{CL}$ was analyzed by in vivo $\left[{ }^{3} \mathrm{H}\right]$-glycerol labeling of $\mathrm{TbCls} \mathrm{KO}$ parasites and revealed that after TbCls depletion for $24 \mathrm{~h}$ no label was incorporated into CL (Fig. $1 \mathrm{E})$, showing that ablation of TbCls expression inhibits $\mathrm{CL}$ synthesis. To examine whether $C L$ depletion leads to defects in mitochondrial structural and functional integrity, we first analyzed mitochondria ultrastructure by transmission electron microscopy. Electron micrographs of TbCls $\mathrm{KO}$ parasites after 0 and $48 \mathrm{~h}$ of $\mathrm{CL}$ depletion showed no obvious morphological defects in mitochondria (Fig. 2A). In contrast, examination of the mitochondrial membrane potential $\Delta \Psi_{\mathrm{m}}$ using the potential-dependent dye MitoTracker Red and fluorescence microscopy revealed that parasites lacked the typical mitochondrial staining observed in control trypanosomes after depletion of TbCls for $24 \mathrm{~h}$ (Fig. 2B). In addition, quantification of the mitochondrial membrane potential in live cells with tetramethylrhodamine ethyl ester (TMRE) using flow cytometry showed a marked reduction in $\Delta \Psi_{\mathrm{m}}$ by $\sim 50 \%$ after $24 \mathrm{~h}$ and $\sim 75 \%$ after $48 \mathrm{~h}$ of $\mathrm{TbCls}$ depletion (Fig. $2 \mathrm{C}$ ). 
A
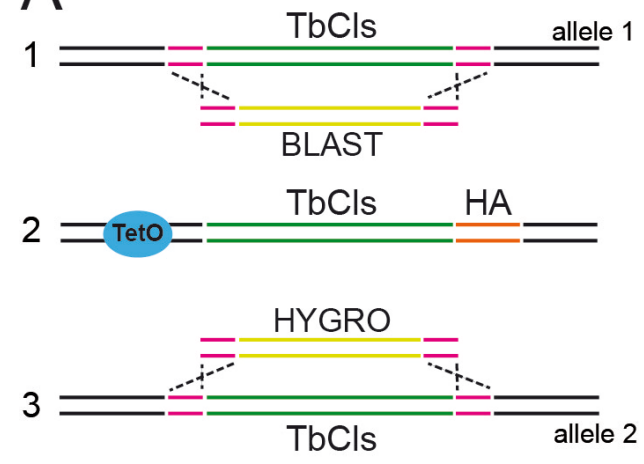

C
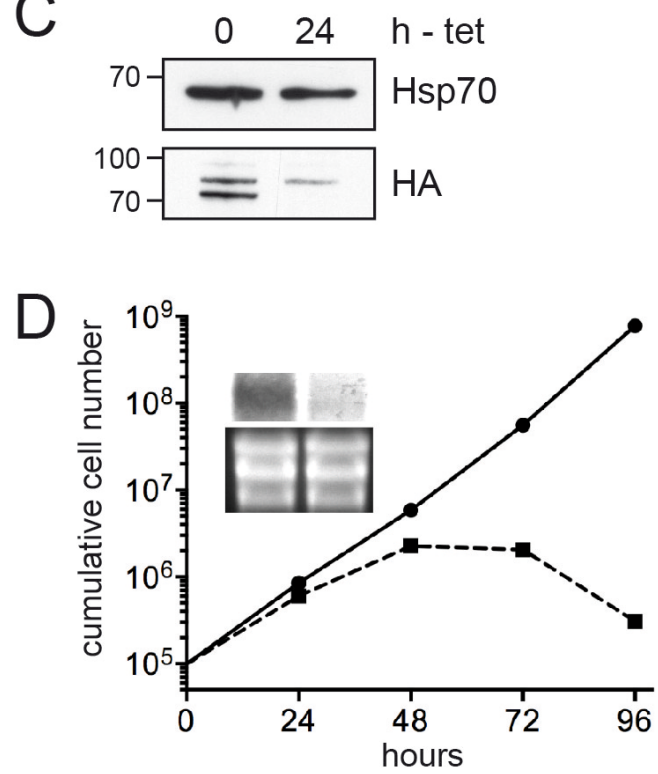

B
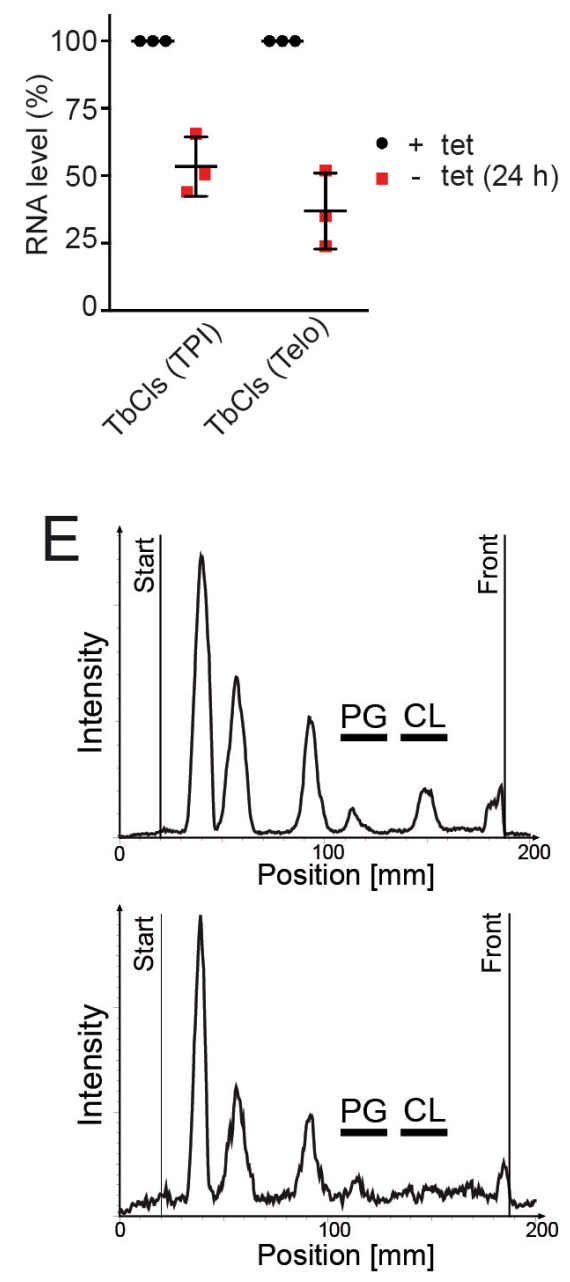

Figure 1: Characterization of conditional TbCls KO bloodstream form parasites. A) The strategy to generate an inducible TbCls $\mathrm{KO}$ involved replacement of one allele with a resistance gene conferring blasticidin resistance, introduction of an ectopic tetracycline-inducible C-terminally HA-tagged TbCls ORF followed by replacement of the second TbCls allele with a hygromycin resistance gene. B) Quantitative PCR assessment of TbCls mRNA after $24 \mathrm{~h}$ of tetracycline removal relative to the two housekeeping genes triosephosphate isomerase (TPI) or telomerase (Telo). C) Immunoprecipitation and immunoblot analysis of HA-tagged TbCls before (0) or after $24 \mathrm{~h}$ of tetracycline removal. Hsp70 was used as input control. D) Growth curve of conditional TbCls KO cells cultured in the presence (filled circles) or absence (filled squares) of tetracycline to induce $\mathrm{TbCls}$ depletion. E) In vivo metabolic labeling of TbCls KO parasites before (top panel) or after TbCls depletion for $24 \mathrm{~h}$ (bottom panel) with $\left[{ }^{3} \mathrm{H}\right]$-glycerol for $6 \mathrm{~h}$ followed by phospholipid extraction and analysis using thin-layer chromatography and radioisotope scanning. 
A

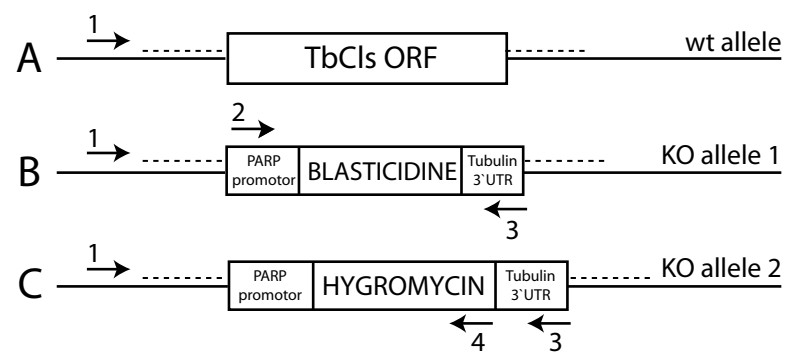

\begin{tabular}{|c|c|}
\hline Primer pair & Expected size \\
\hline $2 / 3$ & $2 \mathrm{~kb}$ \\
\hline $1 / 3$ & $\begin{array}{l}\text { B: } 2.5 \mathrm{~kb} \\
\text { C: } 3 \mathrm{~kb}\end{array}$ \\
\hline $1 / 4$ & $2.4 \mathrm{~kb}$ \\
\hline
\end{tabular}
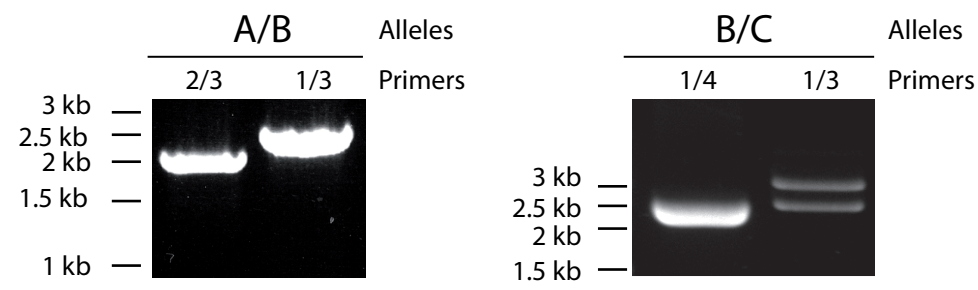

B

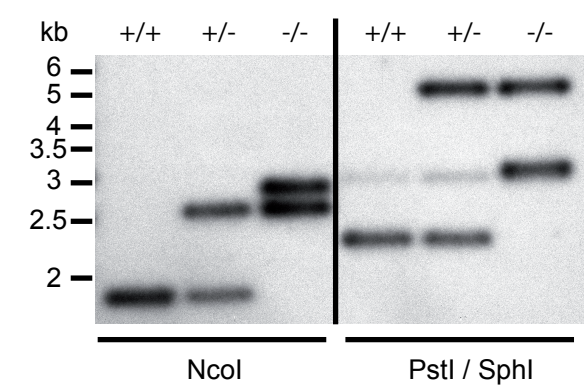

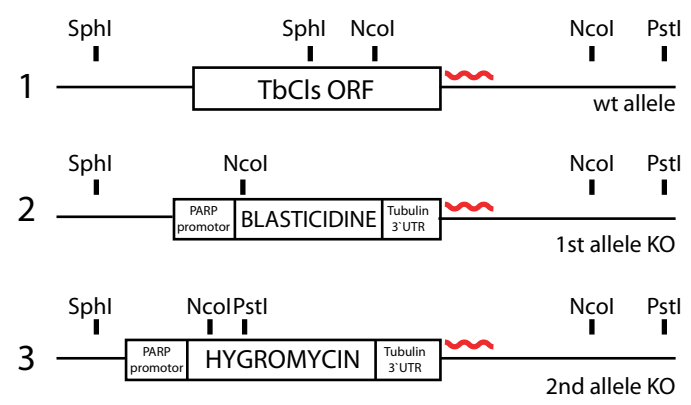

Figure S1: Validation of TbCls $\mathrm{KO}$ parasites. A) PCR verification of single-allele (alleles $A / B$ ) and the final double allele knockout cell line (alleles $B / C$ ). Sizes of expected PCR fragments and primers used for amplification are shown. B) Northern blot analysis of wt (+/+), single-allele (+/-) and double-allele TbCls $\mathrm{KO}(-/-)$ after digestion of genomic DNA with either Ncol or Pstl/Sphl. Expected restriction sites are depicted in the schematic, and the binding site of the hybridizing probe is shown as a red wavy line. 

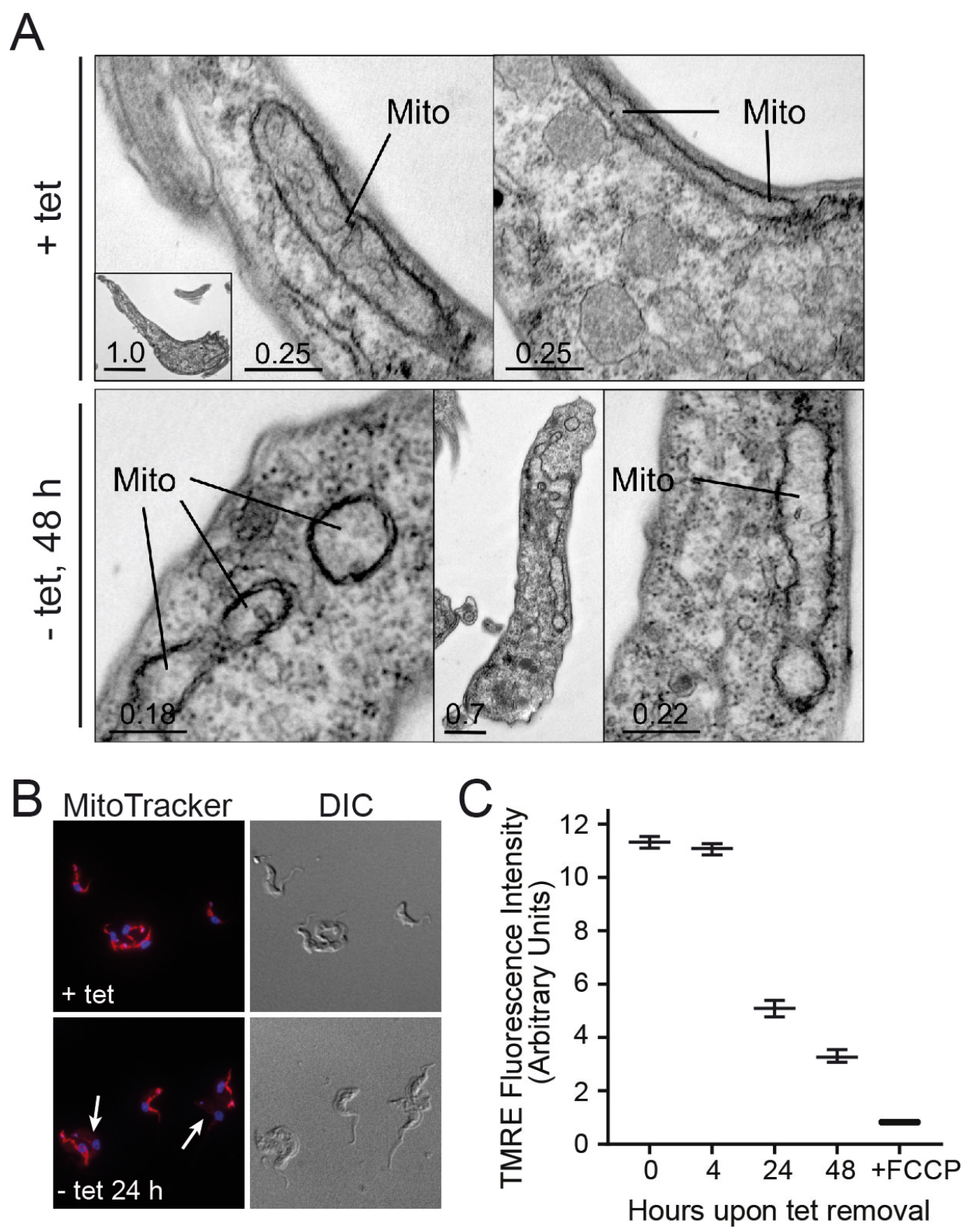

Figure 2: Mitochondrial characterization of $\mathrm{TbCls} \mathrm{KO}$ parasites. A) Transmission electron microscopy of TbCls $\mathrm{KO}$ cells cultured in presence (+ tet) or absence (- tet) of TbCls expression for $48 \mathrm{~h}$. B) MitoTracker staining of live parasites before (+tet) or after (-tet) TbCls depletion for $24 \mathrm{~h}$. Arrows point to cells lacking MitoTracker staining. C) The $\Delta \Psi_{\mathrm{m}}$ of TMRE-stained TbCls $\mathrm{KO}$ cells before (0) or after depletion of TbCls for 4, 24 or $48 \mathrm{~h}$ was measured using flow cytometry. FCCP was used to dissipate $\Delta \Psi_{\mathrm{m}}$. The median fluorescence $\pm \mathrm{S}$. $\mathrm{D}$. from three biological replicates is depicted. 


\section{$1 \quad F_{0} F_{1}-A T P a s e$ complex organization and activity during CL depletion}

In $T$. brucei bloodstream forms, the $\Delta \Psi_{\mathrm{m}}$ is maintained by ATP-dependent

3 proton pumping activity of $\mathrm{F}_{\mathrm{o}} \mathrm{F}_{1}$-ATPase complexes (Nolan \& Voorheis, 1992;

4 Schnaufer, et al., 2005). To test if the drop in $\Delta \Psi_{\mathrm{m}}$ was caused by destabilization of $\mathrm{F}_{\mathrm{o}} \mathrm{F}_{1}$-ATPase complexes as a result of decreased $\mathrm{CL}$ levels, light blue native gel electrophoresis was performed. Native complexes were detected after immunoblotting with specific antibodies against $F_{1}$ subunits $\beta$ and $p 18$ or $F_{0}$ subunit Tb2 (Gahura et al., 2018; Subrtova, Panicucci, \& Zíková, 2015). The results show a mild reduction in the abundance of the monomeric/dimeric state of the $\mathrm{F}_{\mathrm{o}} \mathrm{F}_{1}$-ATPase complex accompanied by an accumulation of the $\mathrm{F}_{1}$ assembly intermediate after $24 \mathrm{~h}$ of $\mathrm{TbCls}$ depletion, which becomes more pronounced after $48 \mathrm{~h}$ of $\mathrm{TbCls}$ depletion (Fig. 3A). To assess the ability of $F_{0} F_{1}-A T P a s e$ complexes to pump protons, we measured uptake of safranin $\mathrm{O}$ into mitochondria of digitonin-permeabilized cells in the presence of exogenously added ATP. Safranin $O$ is a lipophilic cationic dye that, upon membrane potential-dependent uptake into mitochondria, undergoes a spectral change and fluorescence quenching that can be used to estimate $\Delta \Psi_{\mathrm{m}}$ (Figueira, Melo, Vercesi, \& Castilho, 2012). Relative to control parasites expressing TbCls, we observed a $\sim 20 \%$ reduction of safranin O uptake after depletion of TbCls for $24 \mathrm{~h}$, while a decrease of $\sim 40 \%$ was detected after $48 \mathrm{~h}$ of TbCls ablation (Fig. 3B, C, D). The difference between the $\Delta \Psi_{\mathrm{m}}$ measured by TMRE in intact cells (see Fig. 2C) and safranin $O$ uptake measured in digitonin-permeabilized cells in the presence of excess ATP suggests that early during depletion of TbCls, i.e. after $24 \mathrm{~h}$, lack of ATP rather than loss of $F_{0} F_{1}-A T P a s e$ function is responsible for the drop in $\Delta \Psi \mathrm{m}$. Indeed, quantification of the ADP/ATP ratio and total ATP levels after $24 \mathrm{~h}$ of TbCls depletion revealed an increase in the ADP/ATP ratio (Fig. 3E) and a drop in cellular ATP (Fig. 3F) compared to control cells. In summary, after $24 \mathrm{~h}$ of TbCls depletion, $\mathrm{F}_{\mathrm{o}} \mathrm{F}_{1-}$ ATPase structure and activity appear to be only marginally affected, yet the $\Delta \Psi_{\mathrm{m}}$ is strongly reduced, likely due to the drop in cellular ATP. 

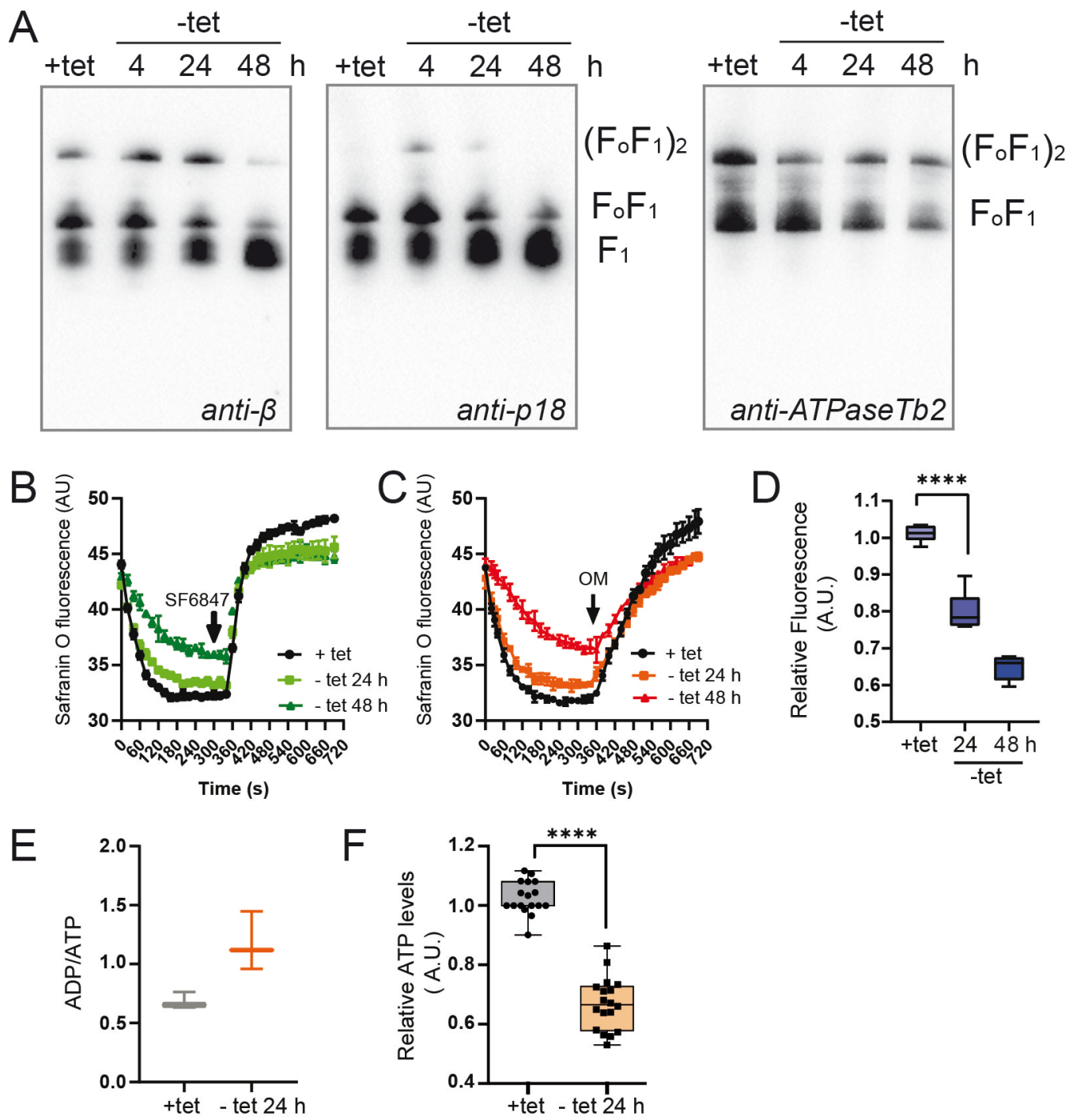

Figure 3: Functional assessment of the mitochondrial $F_{0} F_{1}-A T P$ synthase complex. A) Native $F_{1}$ - and $F_{0} F_{1}$-ATPase complexes were visualized using light blue native electrophoresis. Purified mitochondria from +/-tet cultures were lysed with dodecyl maltoside, fractionated on $3-12 \%$ Bis-Tris gels and blotted onto a PVDF membrane. The $F_{1}$-ATPase and $F_{0} F_{1}$-ATPase monomer and dimers were detected using polyclonal antibodies recognizing $F_{1}$-ATPase subunits $\beta$ and $p 18$, or $F_{0} F_{1}$-ATPase subunit Tb2. B-C) The ability of TbCls KO parasites cultured in the presence (+tet) or absence of tetracycline (-tet) for 24 or $48 \mathrm{~h}$ to establish $\Delta \Psi \mathrm{m}$ in vitro was measured using a fluorescent indicator, safranin $O$, in the presence of excess ATP. The reaction was triggered by addition of digitonin. The extent of the spectral change correlates linearly to $\Delta \Psi \mathrm{m}$. The $\Delta \Psi \mathrm{m}$ was dissipated after the addition of the uncoupler SF6847 (B) or oligomycin (C). D) The fluorescence changes between the time points 0 and $340 \mathrm{~s}$ were normalized to the value of TbCls KO (+tet) and plotted using Graph Pad Prism 8.2.1 $(n=3) ;{ }^{* * \star *} p<0.0001$, Student's t-test). E,F) Comparison of ADP/ATP ratios $(E)$ and cellular ATP content $(F)$ in TbCls KO parasites cultured in the presence 18 (+tet) or absence of tetracycline (-tet) for $24 \mathrm{~h}$ (mean values \pm S.D., $n>3 ;{ }^{* \star * *} \mathrm{p}<$ $0.0001)$. 


\section{$1 \quad$ Metabolomic analyses of TbCls-depleted trypanosomes}

To identify possible metabolic changes caused by $\mathrm{TbCls}$ depletion, we 3 performed metabolomic analyses of parasites after $12 \mathrm{~h}$ and $24 \mathrm{~h}$ of TbCls depletion and compared metabolite levels to control cells. Interestingly, of a total of 5050 detected peaks, we observed significant changes ( $p$-values <0.05) in several key

6 metabolites associated with energy deprivation. While the levels of phosphoarginine, 7 acetoacetate and oxidized hexoses were decreased, AMP levels were increased 8 (Table 1). Phosphoarginine represents the equivalent to phosphocreatine in 9 vertebrates by providing high-energy phosphate groups to replenish ATP levels on a short time-scale and is produced by multiple isoforms of phosphoarginine kinases (Voncken, Gao, Wadforth, Harley, \& Colasante, 2013). Acetoacetate represents a ketone body produced under conditions of starvation and has been identified in $T$. brucei before (Shah, Hickey, Capasso, \& Palenchar, 2011), whereas oxidized hexoses, e.g. D-gluconate, are substrates for the pentose-phosphate pathway for nucleotide biosynthesis and formation of NADPH, a key reducing agent for protection against oxidative stress in trypanosomes (Kovarova \& Barrett, 2016).

\begin{tabular}{|c|l|}
\hline Log2 fold change (24h) & \multicolumn{1}{c|}{ Metabolite } \\
\hline-7.63 & Tetracycline \\
-2.20 & Torachrysone 8-glucoside \\
-2.14 & 10-formyldihydrofolate \\
-1.86 & Nocardicin c \\
-1.57 & kaempferol 3-(2"-acetylrhamnoside) \\
-1.53 & Phosphoarginine \\
-1.29 & (s)-dihydroorotate \\
-0.84 & Galactonic acid \\
-0.84 & D-Gluconic acid (or other oxidized hexose) \\
-0.69 & L-Cystathionine \\
-0.51 & Acetoacetate \\
-0.38 & L-Threonine \\
0.49 & Ethanolamine phosphate \\
0.73 & sn-Glycerol-3-phosphate \\
0.78 & Guanine \\
1.30 & I-n2-(2-carboxyethyl)arginine \\
1.79 & AMP \\
\hline
\end{tabular}

Table1: Metabolomic changes triggered by depletion of TbCls. List of mass spectrometry signals matched to known standards. The log2 fold change between metabolites found in parasites expressing TbCls and depleted of $\mathrm{TbCls}$ for $24 \mathrm{~h}$ are listed. Metabolites shown had a significance at a p-value of $<0.05$. 
2 (Gloaguen et al., 2017) revealed no consistent changes in metabolite levels in the

3 glycolytic pathway, the TCA cycle or amino acid metabolism, while glycerolipid metabolism was the most significantly changed pathway between control and $24 \mathrm{~h}$ TbCls-depleted parasites, highlighted by increased levels of glycerol and glycerol-3phosphate (Fig. S2). Together, the metabolomic analyses support the above observations that parasites after $24 \mathrm{~h}$ of TbCls depletion are in an energy-deprived state.

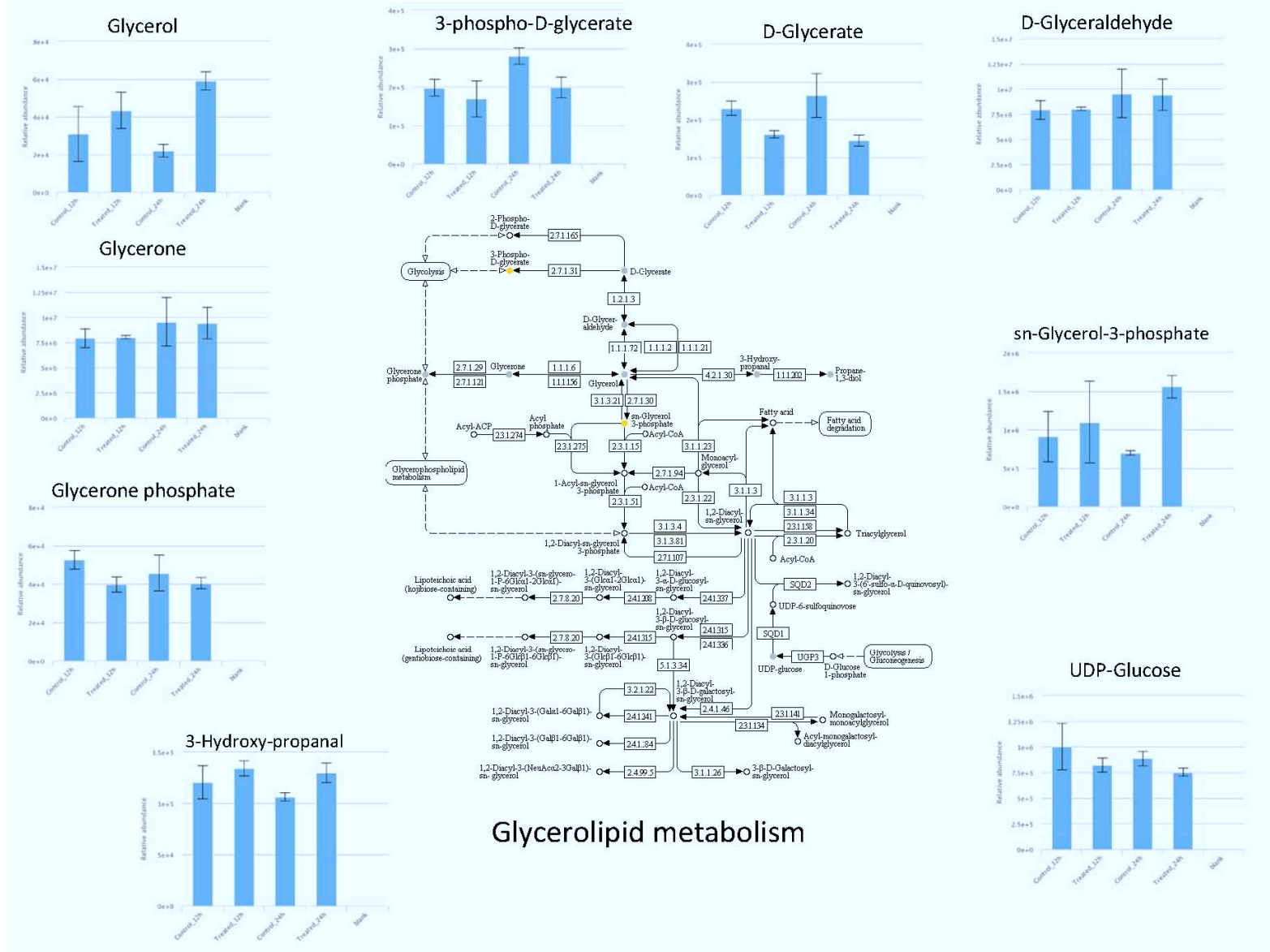

Figure S2: Changes of metabolite levels of glycerolipid metabolism. The blue bars depict metabolite levels of control (+ tet, $0 \mathrm{~h})$, TbCls depleted (-tet, 12h), control (+ tet, $24 \mathrm{~h}$ ) and TbCls depleted (-tet, $24 \mathrm{~h}$ ) parasites, respectively. 


\section{$1 \quad$ Proteomic changes during CL depletion}

Using stable isotope labeling with amino acids in cell culture (SILAC) and mass spectrometry we subsequently compared the proteomes of mitochondriaenriched extracts from T. brucei bloodstream forms after depletion of TbCls for $12 \mathrm{~h}$ and $24 \mathrm{~h}$ with parasites expressing TbCls. Previous experiments have shown that labeled amino acids are uniformly incorporated into the proteome in $T$. brucei parasites (Cirovic \& Ochsenreiter, 2014; Schädeli, et al., 2019) and that parasite growth was not affected by the different culture media used for SILAC (Fig. S3).

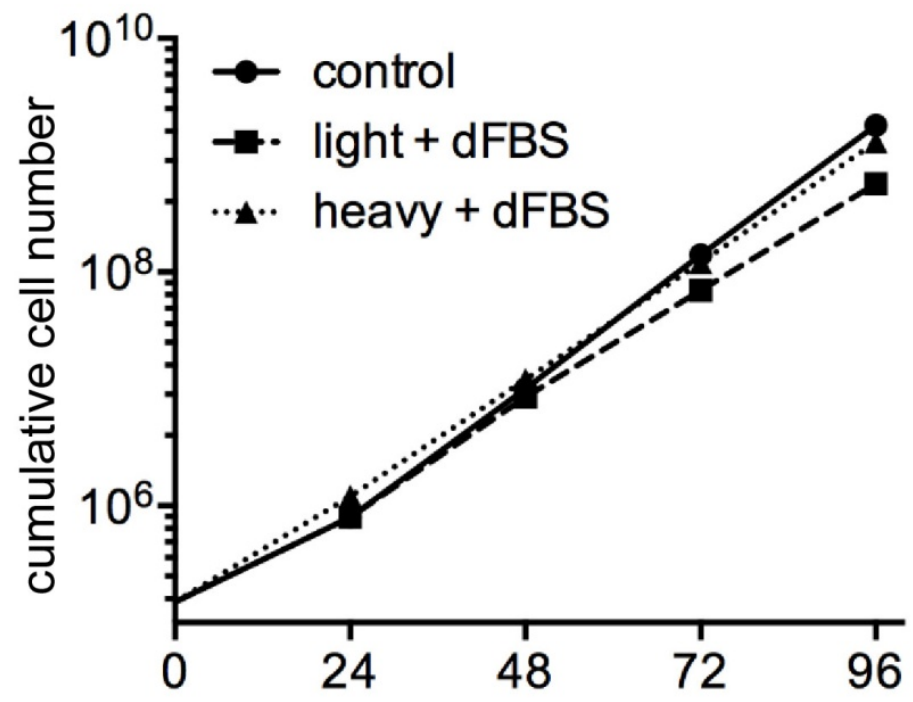

hours

Figure S3: Growth of TbCls $\mathrm{KO}$ parasites cultured in light and heavy medium containing normal or isotope-labeled amino acids. Parasites were cultured in medium containing L-arginine and L-lysine and dialyzed fetal bovine serum (light $+\mathrm{dFBS}$ ) or isotope labeled L-arginine and L-lysine with dialyzed fetal bovine serum (heavy + dFBS). Control parasites were cultured in light medium with non-dialyzed fetal bovine serum (control).

Our analyses revealed $>1100$ proteins in each of the biological triplicates from all three time points ( $0 \mathrm{~h}, 12 \mathrm{~h}$ and $24 \mathrm{~h}$ of TbCls ablation). We identified a large number of proteins with altered expression levels after $12 \mathrm{~h}$ and $24 \mathrm{~h}$ of TbCls depletion compared to control trypanosomes (Fig. 4A-C), with $>110$ proteins with fold-changes of down-regulation of $\geq 1.6$ (Fig. 4D, Table S1) and $>35$ proteins with fold-changes of up-regulation of $\geq 1.4$ (Fig. 4D, Table S2). 

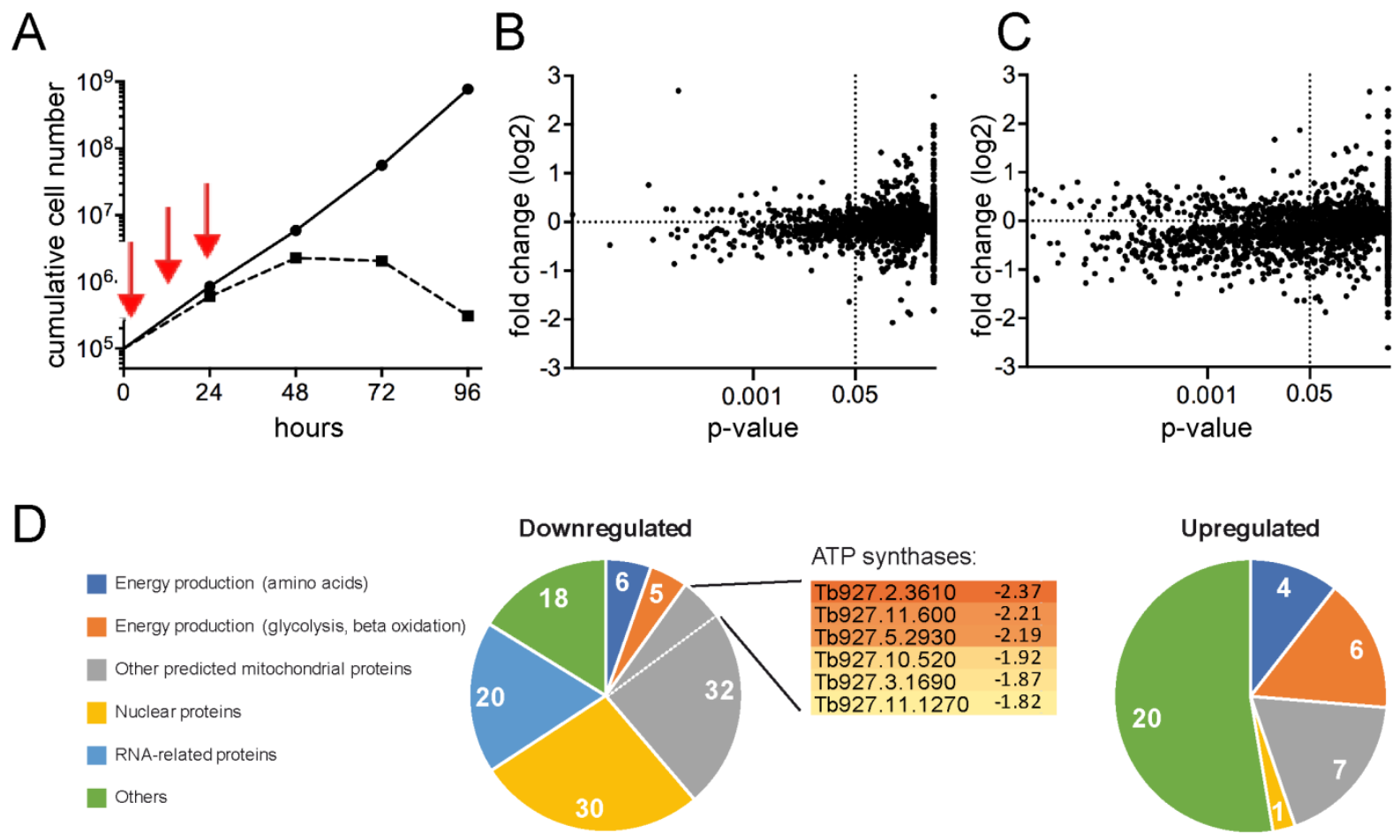

$E$

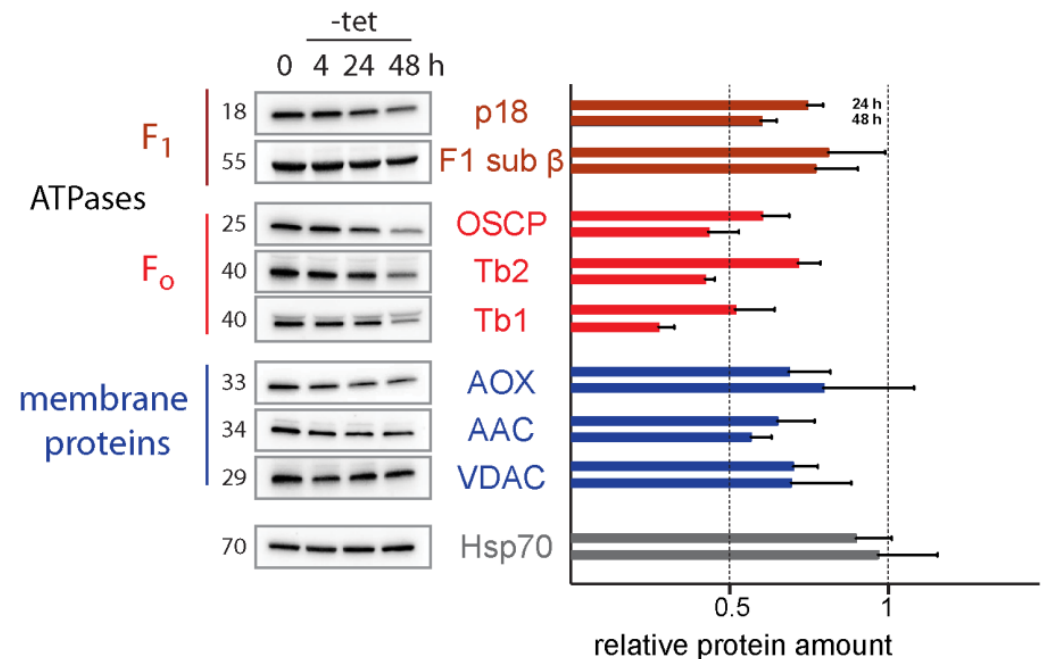

Figure 4: Cardiolipin-induced changes in protein levels. A-C) SILAC analysis of protein abundance during depletion of TbCls. Membrane-enriched fractions from TbClsKO parasites cultured for $0 \mathrm{~h}, 12 \mathrm{~h}$ or $24 \mathrm{~h}$ (indicated by red arrows in $\mathrm{A}$ ) in the absence of tetracycline to induce ablation of $\mathrm{TbCls}$ expression were analyzed by mass spectrometry. The $p$-value of each data point was determined by a two-sample t-test between time points $0 \mathrm{~h}$ and $12 \mathrm{~h}(\mathrm{~B})$ and $0 \mathrm{~h}$ and $24 \mathrm{~h}(\mathrm{C})$ from three biological independent experiments and was plotted against the fold change in protein abundance after $12 \mathrm{~h}$ and $24 \mathrm{~h}$, respectively, relative to the control sample taken at time $0 \mathrm{~h}$. D) Grouping of proteins that were down- or up-regulated upon TbCls depletion for $24 \mathrm{~h}$. Gene IDs for down-regulated ATP synthase subunits are shown. E) Immunoblot analyses of TbCls $\mathrm{KO}$ cells grown in the presence (0) or absence of tetracycline for 4,24 and $48 \mathrm{~h}$. Signals from -tet samples are shown relative to control samples $(n \geq 3)$. 
1 Among the down-regulated proteins, (predicted) mitochondrial proteins comprised 2 the largest group (Fig. 4D, Table S1). Interestingly, we identified two known subunits 3 of ATP synthase, Tb1 (Tb927.10.520) and Tb2 (Tb927.5.2930), and several proteins annotated as novel subunits of ATP synthase (Tb927.2.3610, Tb927.11.600, Tb927.3.1690, Tb927.11.1270) (Fig. 4D, Table S1). In addition, among the downregulated proteins, we identified six (putative) proteins involved in amino acid metabolism, with two of them representing putative amino acid transporters of the AAT4 family with unknown specificities and localization (Tb927.4.4830/4850/4870; Tb927.4.4860), one being a putative mitochondrial amino acid transporter of the AAT17 family (Tb927.11.15950) and the other annotated as putative lysine transport protein (Tb927.11.15840/15860). Furthermore, down-regulation was also observed for several mitochondrial and cytosolic proteins involved in energy metabolism, such as putative enoyl-CoA hydratase (Tb927.11.16480), malic enzyme (Tb927.11.5450), putative hydroxymethylglutaryl-CoA lyase (Tb927.4.2700), putative acyl-CoA synthetase (Tb927.6.2010), putative NADH-cytochrome b5 reductase (Tb927.5.1470), putative adenylate kinase (Tb927.10.2540) and pyruvate kinase 1 (Tb927.10.14140). The list of down-regulated proteins also comprised proteins involved in nucleotide metabolism (two adenosine transporters, ribonucleosidediphosphate reductase) and $N$-glycosylation (putative dolichyl-P-Man:GDPMan7GlcNAc2-PP-dolichyl alpha-1,6-mannosyltransferase, putative UDP-Gal/UDPGlcNAc-dependent glycosyltransferase) and two large sets with nuclear/nucleolar proteins and proteins involved in RNA synthesis/processing (Table S1).

Among the up-regulated proteins, we identified proteins involved in energy production via carbohydrate metabolism, including the bloodstream form-specific glucose transporter THT1 (Tb927.10.8440), hexokinase (Tb927.10.2010), fructosebisphosphate aldolase (Tb927.10.5620) and glyceraldehyde 3-phosphate dehydrogenase (Tb927.10.6880) (Fig. 4D, Table S2), and several mitochondrial enzymes connecting amino acid metabolism to the TCA cycle, such as glutamate dehydrogenase (Tb927.9.5900), putative hydroxyglutarate dehydrogenase (Tb927.10.9360), putative 2-oxoglutarate dehydrogenase, component E1 (Tb927.11.9980) and succinate dehydrogenase assembly factor 2 (Tb927.6.2510). Remarkably, several nutrient and ion transporters ranked among the most highly upregulated proteins, such as putative mitochondrial amino acid transporter AAT7 
1 (Tb927.8.7610/8.7640; 2.3-fold up-regulation), aquaglyceroporin 1 (Tb927.6.1520; 2 2.1-fold up-regulation), mitochondrial folate transporter (Tb927.8.3650; 1.9-fold up3 regulation) and putative mitochondrial V-type ATPase (Tb927.4.1080; 1.5-fold up4 regulation).

To verify CL-dependent down-regulation of selected mitochondrial proteins, protein extracts from $T$. brucei bloodstream forms after down-regulation of $\mathrm{TbCls}$ were analyzed by SDS-PAGE and immunoblotting using antibodies recognizing $\mathrm{F}_{\mathrm{o}} \mathrm{F}_{1}$ ATPase subunits, mitochondrial membrane proteins or mitochondrial matrix proteins (Fig. 4E). The results after TbCls depletion revealed decreased levels of several $F_{\circ}$ subunits ( $>20$ and $>50 \%$ reduction after $24 \mathrm{~h}$ and $48 \mathrm{~h}$, respectively) and $\mathrm{F}_{1}$ subunits (>20\% reduction after $24 \mathrm{~h}$ ) of the $\mathrm{F}_{\mathrm{o}} \mathrm{F}_{1}$-ATPase complex (Fig. 4E, top two panels) and the inner mitochondrial membrane proteins alternative oxidase (AOX; Tb927.10.7090; $25 \%$ reduction after $24 \mathrm{~h}$ ) and ADP/ATP carrier (AAC; Tb927.10.14830; $\sim 30 \%$ reduction after 24 h) (Fig. 4E, middle panel). These results are in line with the SILAC/mass spectrometry data showing reduced levels of several ATP synthase subunits (see Table S1) and a reduction in AOX ( 20\% decrease after $24 \mathrm{~h}$; AAC was not detected in the SILAC experiments).

In bloodstream form trypanosomes, glycolysis and thus ATP production is directly coupled to mitochondrial respiration via a truncated ETC composed of glycerol-3-phosphate dehydrogenase and alternative oxidase (Opperdoes, Borst, Bakker, \& Leene, 1977). To assess if the CL-induced drop in ATP levels is linked to decreased cellular respiration, we measured oxygen consumption rates of live parasites during the depletion of TbCls. Our results show that $\mathrm{O}_{2}$ consumption after $24 \mathrm{~h}$ and $48 \mathrm{~h}$ of CL depletion was significantly reduced relative to control cells (Fig. $5 A, B)$. Since $A O X$ is a dimer bound to the inner mitochondrial membrane via a hydrophobic region in an interfacial fashion (Shiba et al., 2013), we tested if CL may be involved in membrane binding of AOX. We performed carbonate extraction experiments with isolated mitochondria from parasites before and after depletion of $\mathrm{CL}$ and found that $\mathrm{AOX}$ expression is indeed decreased (Fig. 5C; see also Fig. 4E), however, partitioning of AOX between pellet and supernatant fractions was unchanged between TbCls-depleted and control parasites (Fig. 5C), demonstrating that depletion of CL affected AOX steady-state levels but not binding to the inner mitochondrial membrane. 

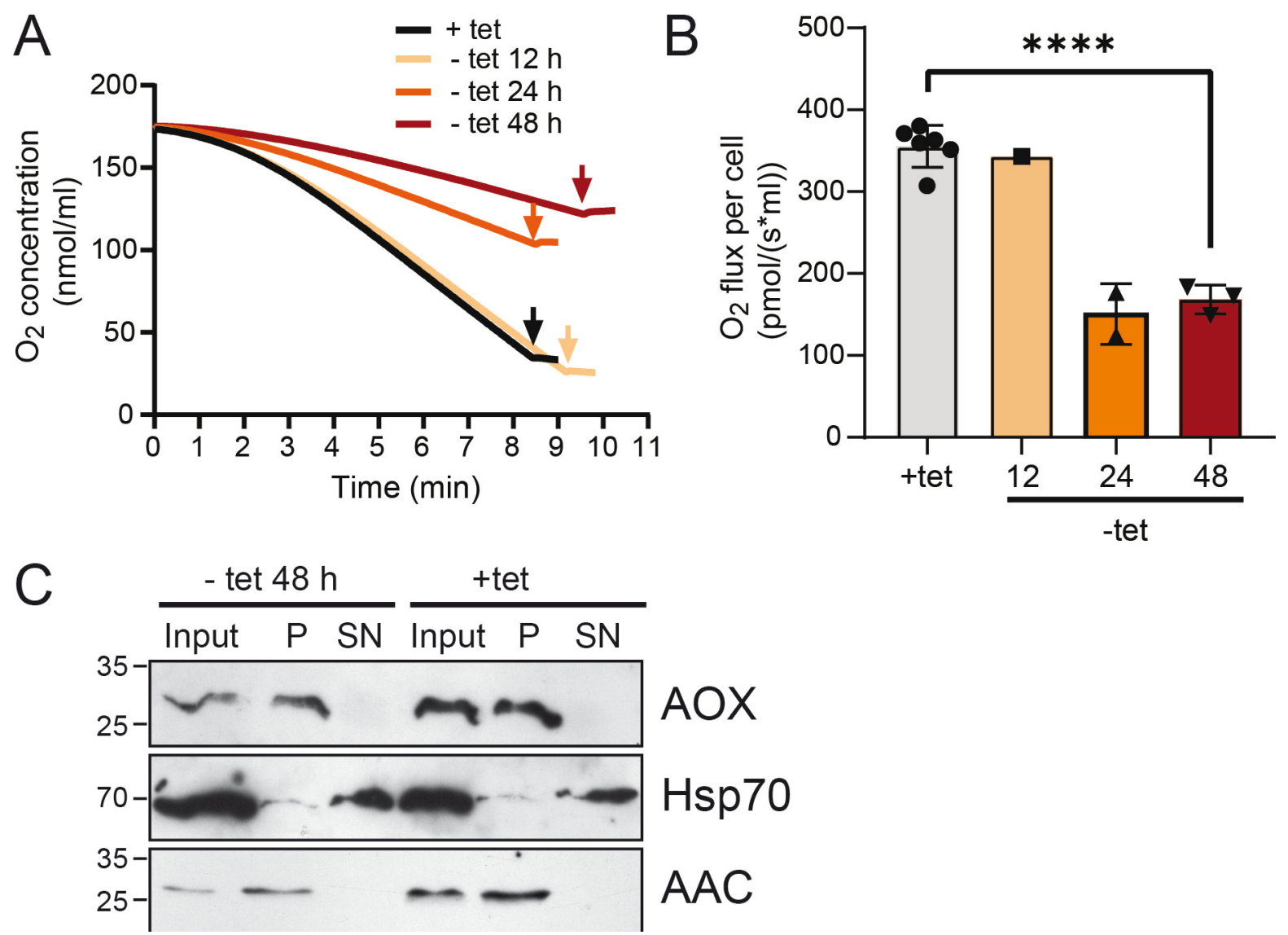

Figure 5: Oxygen consumption is affected by $\mathrm{CL}$ depletion. A) Representative respiratory traces of TbCls KO parasites cultured in the presence (+tet) or absence of tetracycline (-tet) for 24 or $48 \mathrm{~h}$ were determined using high-resolution respirometry (Oroboros Instrument). The graphs depict changes in oxygen concentration (nmol/ml) 9 in the media over time (x-axes) (left panel). Arrows indicate time of addition of the 10 inhibitor SHAM. B) Oxygen flow in TbCls KO parasites cultured in the presence (+tet) 11 or absence of tetracycline (-tet) for 24 or $48 \mathrm{~h}$ is expressed as respiration per million

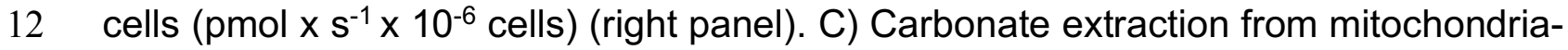
enriched fractions of TbCls $\mathrm{KO}$ parasites grown in presence or absence of $\mathrm{TbCls}$ expression for $48 \mathrm{~h}$. Fractionation of AOX was compared to the soluble protein Hsp70 and the integral membrane protein AAC. 


\section{Discussion}

High-resolution structures have revealed specific binding of $\mathrm{CL}$ to mammalian and yeast respiratory complexes I (Fiedorczuk, et al., 2016), III (Lange, et al., 2001; Solmaz \& Hunte, 2008) and IV (Shinzawa-Itoh, et al., 2007) of the inner mitochondrial membrane. In addition, CL stimulates the activities of these complexes and stabilizes super-complex formation (Mileykovskaya \& Dowhan, 2014). As a result, in CL-deficient mammalian, yeast and plant cells, mitochondrial ultrastructure and function, in particular respiration, is affected. In spite of these defects, the cells are viable (Jiang, Rizavi, \& Greenberg, 1997; Pineau et al., 2013; Raemy, et al., 2016). In contrast, $C L$ is essential for the survival of $T$. brucei procyclic forms in culture (Serricchio \& Bütikofer, 2012, 2013). Here, we investigated the effects of CL depletion in T. brucei bloodstream forms, i.e. in cells lacking a functional ETC and ATP production via oxidative phosphorylation (Hannaert, et al., 2003).

To control de novo CL synthesis, we deleted both alleles of TbCls in $T$. brucei bloodstream forms and introduced a tetracycline-dependent copy of HAtagged TbCls. Upon removal of tetracycline from the culture medium, TbCls expression was down-regulated and de novo synthesis of CL was inhibited. These conditions resulted in growth arrest of parasites followed by cell death, demonstrating that the production of $\mathrm{CL}$ in $T$. brucei bloodstreams forms is essential for parasite survival in culture.

Interestingly, after inhibition of CL synthesis, proteomic analyses revealed markedly reduced levels of many mitochondrial proteins. Most notably, several confirmed and predicted subunits of the inner mitochondrial membrane $F_{0} F_{1}-A T P$ synthase were severely down-regulated. $\mathrm{CL}$ is tightly associated with $\mathrm{F}_{0} \mathrm{~F}_{1}$-ATP synthase, (Eble, Coleman, Hantgan, \& Cunningham, 1990; Muhleip, McComas, \& Amunts, 2019), and crystal structures have revealed CL binding sites in the rotorstator interface, the dimer interface, and in a peripheral $F_{0}$ cavity (Muhleip, et al., 2019). Molecular modeling suggests that CL participates in proton translocation through the membrane domain (Duncan, Robinson, \& Walker, 2016). Upon CL depletion in Drosophila flight-muscle mitochondria, $F_{0} F_{1}-A T P$ dimers are destabilized and their lateral membrane distribution is distorted (Acehan, et al., 2011). In T. brucei bloodstream forms, we observed destabilization of $F_{0} F_{1}-A T P$ dimers as well as monomers during $C L$ depletion leading to accumulation of $F_{1}$-ATPase subcomplex. 
1 naturally occurring and drug-induced dyskinetoplastic bloodstream form 2 trypanosomes (Schnaufer, Domingo, \& Stuart, 2002), which maintain the 3 mitochondrial membrane potential in an $\mathrm{F}_{\mathrm{o}}$-independent fashion (Schnaufer, et al., 2005) by coupling $F_{1}$-ATPase activity with electrogenic exchange of the cytosolic ATP $^{4-}$ for the mitochondrial matrix ADP $3-$ by the AAC. However, this mechanism is conditioned by acquiring specific mutations in the $F_{1}$ subunits (Dean, Gould, Dewar, \& Schnaufer, 2013; Lai, Hashimi, Lun, Ayala, \& Lukes, 2008), which presumably increase the enzyme's capacity to hydrolyze ATP. Without these mutations, bloodstream form cells are not capable of maintaining mitochondrial membrane potential in an $\mathrm{F}_{\mathrm{o}}$-independent mode (Schnaufer, et al., 2005). These observations are consistent with our results of the $\Delta \Psi_{\mathrm{m}}$ measurements in vivo by TMRE and in vitro by safranin $\mathrm{O}$ at $48 \mathrm{~h}$ of $\mathrm{CL}$ depletion. The decreased levels of the coupled $\mathrm{F}_{\mathrm{o}} \mathrm{F}_{1-}$ ATPase led to a substantial drop in $\Delta \Psi \mathrm{m}$. Interestingly, at $24 \mathrm{~h}$ of TbCls depletion, the $\Delta \Psi_{\mathrm{m}}$ measured in vivo by TMRE was already decreased by $50 \%$, while in vitro safranin $O$ uptake measurements in presence of excess ATP revealed only a $20 \%$ reduction in $\Delta \Psi_{\mathrm{m}}$, suggesting that at this early timepoint it is the lack of the substrate, i.e. ATP, rather than the dysfunctional $F_{0} F_{1}-A T P a s e$ that leads to the observed $\Delta \Psi_{\mathrm{m}}$ phenotype.

In addition to a down-regulation of $\mathrm{F}_{\mathrm{o}} \mathrm{F}_{1}$-ATP synthase subunits, $\mathrm{CL}$ depletion resulted in a decrease of several (putative) transporters. It has been shown before that $\mathrm{CL}$ associates with and affects the activity of the mitochondrial AAC (Beyer \& Klingenberg, 1985; Claypool, Oktay, Boontheung, Loo, \& Koehler, 2008). In addition, $\mathrm{CL}$ stimulates the activities of the carnitine/acylcarnitine transporter (Paradies, Ruggiero, Petrosillo, \& Quagliariello, 1997) and the phosphate carrier (Kadenbach, Mende, Kolbe, Stipani, \& Palmieri, 1982), and it is possible that additional mitochondrial carriers also depend on CL for proper function (Claypool, 2009). Although the subcellular localization of several of the T. brucei transporters downregulated after CL depletion has not been experimentally established, our data suggest that they may localize to the inner mitochondrial membrane, where they interact with $\mathrm{CL}$ and become depleted after inhibition of de novo CL synthesis. Two mitochondrial amino acid transporters, amino acid transporter AAT17 (Tb927.11.15950) and L-lysin transport protein (Tb927.11.15840), which have not yet been associated with $\mathrm{CL}$, were down-regulated as well. Whether or not they bind $\mathrm{CL}$ and are down-regulated as a direct consequence of CL depletion is not clear, but 
1 deserves further attention. Similarly, although the association of AOX with the inner 2 mitochondrial membrane was not disrupted during CL depletion, its expression was 3 decreased. It is conceivable that the observed decrease in oxygen consumption by AOX is a direct consequence of reduced CL levels. The T. brucei bloodstream form cellular respiration is coupled to the glycerol-3-phosphate/dihydroxyacetone phosphate shuttle in which the mitochondrial FAD-linked glycerol-3-phosphate dehydrogenase oxidizes glycerol-3-phosphate to dihydroxyacetone phosphate and passes electrons to ubiquionone (Opperdoes, et al., 1977). The reduced ubiquinone is then oxidized by AOX. Mitochondrial glycerol-3-phosphate dehydrogenase is tightly bound to the inner mitochondrial membrane and was proposed to function in a cardiolipin-dependent fashion (Beleznai \& Jancsik, 1989). It is possible that in the absence of $\mathrm{CL}, \quad T$. brucei glycerol-3-phosphate dehydrogenase becomes dysfunctional, and glycerol-3-phosphate is instead converted to glycerol by glycerol kinase in glycosomes, thereby resembling anaerobic conditions during which only 1 molecule of ATP is produced per 1 molecule of glucose (Bakker, Michels, Opperdoes, \& Westerhoff, 1997). Indeed, the ablation of $\mathrm{TbCls}$ expression led to decreased ATP levels. Further, we also observed an accumulation of glycerol-3phosphate and glycerol, indicating an improper function of glycerol-3-phosphate dehydrogenase. Interestingly, accumulation of glycerol is known to be toxic for $T$. brucei parasites, which may explain the observed increased expression of aquaglyceroporins, the transporters mediating glycerol efflux (Uzcategui et al., 2004), during $C L$ depletion.

In addition, ablation of $\mathrm{TbCls}$ expression resulted in down-regulation of several mitochondrial and cytosolic enzymes. Since none of them is predicted to contain a transmembrane domain, we believe that their decrease was not a direct effect of CL depletion but a result of metabolic alterations (see below). The two sets of proteins comprising down-regulated nuclear/nucleolar proteins and proteins involved in RNA synthesis/processing likely reflect the parasite's reduced metabolism and slowed growth after prolonged CL depletion. Together, these observations indicate that the primary effect of CL depletion in T. brucei bloodstream forms is on cellular respiration and the structural organization and activity of the $F_{\circ} F_{1}-A T P$

32 synthase, leading to a progressive loss of the mitochondrial membrane potential and 33 a dramatic increase in the ADP/ATP ratio as well as steady-state levels of several 34 (mitochondrial) transporters. 
Unexpectedly, and in contrast to previous findings in procyclic forms 2 (Schädeli, et al., 2019), depletion of CL in T. brucei bloodstream forms led to an 3 increase in the levels of a large number of proteins (Table S2). Many of these 4 proteins are involved in metabolic reactions and pathways to increase ATP production. Increases in glutamate dehydrogenase (Tb927.9.5900), (putative) hydroxyglutarate dehydrogenase (Tb927.10.9360) and 2-oxoglutarate dehydrogenase (Tb927.11.9980), as well as in (putative) amino acid transporter AAT7 (Tb927.8.7610), are consistent with up-regulation of amino acid metabolism, in particular glutamate catabolism. As reported before, T. brucei bloodstream forms consume large quantities of glutamine, primarily as an amino group donor (Creek et al., 2013; Kim, Achcar, Breitling, Burgess, \& Barrett, 2015). Recent intracellular metabolome analyses using ${ }^{13} \mathrm{C}$-labeled tracking confirmed that glutamine is catabolized to glutamate and on to 2-oxoglutarate and succinate (Johnston et al., 2019). Among the different possible pathways leading to production of succinate from glutamate (Johnston, et al., 2019), our proteomic data suggest that - during CL depletion - glutamate dehydrogenase (1.6-fold up-regulated) converts glutamate to 2-oxoglutarate which is then metabolized to succinate by 2-oxoglutarate dehydrogenase (1.74-fold up-regulated and succinyl-CoA synthetase (Tb927.3.2230, 1.12-fold up-regulated) to produce ATP. In addition, 2-oxoglutarate can be converted to hydroxyglutarate by promiscuous action of malate dehydrogenase (Intlekofer et al., 2017) (Tb927.10.2560, 1.23-fold up-regulated) and back to 2-oxoglutarate by hydroxyglutarate dehydrogenase (1.74-fold up-regulated). Although the substrate specificity of (putative) amino acid transporter AAT7 (2.3-fold up-regulated) is currently unknown, we propose that it may be responsible for the increased uptake of glutamine into the mitochondrion of bloodstream form trypanosomes. Alternatively, increased production of glutamate could also result from AAT7-mediated uptake of proline with subsequent degradation by proline dehydrogenase (Tb927.7.210; not detected in our study) and $\Delta 1$-pyrroline-5carboxylate dehydrogenase (Tb927.10.3210; not detected in our study).

Furthermore, our data revealed increased levels of additional enzymes and transporters involved in energy production in T. brucei (Table S2). Up-regulation of the glycolytic enzymes hexokinase (Tb927.10.2010), glyceraldehyde-3-phosphate dehydrogenase (Tb927.10.6880) and fructose-bisphosphate aldolase 34 (Tb927.10.5620), and of hexose transporter THT1 (Tb927.10.8440), are again 
1 consistent with the parasite's metabolic response to counteract CL-induced depletion 2 of ATP. The severity of energy depletion is further reflected in a decrease in 3 phosphoarginine levels and an increase in the arginine metabolite N2-(2carboxyethyl)arginine. In a recent report, it was shown that in T. brucei bloodstream forms phosphoarginine is exclusively generated by the action of arginine kinases (Johnston, et al., 2019). Although arginine kinase knock-out parasites were viable in culture (Johnston, et al., 2019), it is believed that phosphoarginine plays a central role in regenerating ATP from ADP in situations of high (short term) energy demand (Pereira, Alonso, Torres, \& Flawia, 2002).

Remarkably, while the analysis of the proteome during $C L$ depletion revealed a pronounced decrease in the levels of several subunits of the inner mitochondrial membrane $\mathrm{F}_{\mathrm{o}} \mathrm{F}_{1}$-ATP synthase (Table $\mathrm{S} 1$; see also above), one protein annotated as putative ATP synthase subunit (Tb927.11.9420, 1.4-fold up-regulated) was found to be increased (Table S2). Interestingly, the protein has been described as a subunit of the peripheral stalk of the vacuolar $\mathrm{H}^{+}$-ATPase (Huang et al., 2014). T. brucei bloodstream forms use V-type ATPases and mitochondrial ATPases to generate proton gradients (Schnaufer, et al., 2005), and recently functional interdependency between both types of ATPases has been reported (Baker et al., 2015). Knockdowns of V-type ATPase subunits were shown to induce kinetoplast independence and resistance of trypanosomes to isometamidium, a DNA intercalating drug that accumulates in the kinetoplast, indicating that loss of V-type ATPases affects $F_{0} F_{1-}$ ATP synthase sector coupling (Baker, et al., 2015). The function of the up-regulated V-type ATPase subunit during CL depletion is not known. The observation that depletion of V-type ATPase allows for kinetoplast-independent growth (Baker, et al., 2015) suggests, however, that it's levels were increased in response to the observed CL-dependent $F_{\circ} F_{1}$-ATP synthase sector uncoupling. 


\section{Methods}

Unless otherwise stated, reagents were purchased from Sigma (Buchs, 3 Switzerland) or Merck (Darmstadt, Germany). Restriction enzymes were from 4 Thermo Scientific (Reinach, Switzerland), DNA amplification and processing was performed with reagents from Promega (Dübendorf, Switzerland).

Trypanosome cultures

Bloodstream form TbCls $\mathrm{KO}$ parasites were cultured at $37{ }^{\circ} \mathrm{C}$ in $\mathrm{HMI}-9$ containing $15 \%(\mathrm{v} / \mathrm{v})$ heat-inactivated fetal bovine serum, $1 \mu \mathrm{g} / \mathrm{ml} \mathrm{G} 418,0.5 \mu \mathrm{g} / \mathrm{ml}$ hygromycin, $0.1 \mu \mathrm{g} / \mathrm{ml}$ puromycin, $1 \mu \mathrm{g} / \mathrm{ml}$ blasticidin (InvivoGen, Muttenz, Schweiz), and in the presence or absence of $1 \mu \mathrm{g} / \mathrm{ml}$ tetracycline to maintain or ablate, respectively, $\mathrm{TbCls}$. TbCls $\mathrm{KO}$ parasites expressing in-situ-tagged proteins were cultured in the presence of an additional $1.5 \mu \mathrm{g} / \mathrm{ml}$ phleomycin.

\section{Generation of TbCls conditional knock-out mutants}

To generate plasmids to replace the endogenous $\mathrm{TbCls}$ genes, blasticidin and hygromycin resistance cassettes consisting of a PARP promoter, the resistance gene and a tubulin 3' UTR were amplified from pXS2 expression vectors (courtesy of James D. Bangs, University of Buffalo, NY) and inserted into a plasmid containing 400 bp long recombination sequences flanking the TbCls ORF (Serricchio \& Bütikofer, 2012). Prior to transfections into NY single marker bloodstream forms (Wirtz, Leal, Ochatt, \& Cross, 1999), plasmids were cut upstream and downstream of the recombination sequences using Xhol and Notl. The inducible hemagglutinin (HA)-tagged ectopic copy of TbCls was constructed by PCR amplification of the Tb927.4.2560 ORF as described (Serricchio \& Bütikofer, 2012). Prior to transfection, the vector was linearized with Notl. Clones were obtained by limiting dilution and antibiotic selection using $1 \mu \mathrm{g} / \mathrm{ml}$ blasticidin, $0.1 \mu \mathrm{g} / \mathrm{ml}$ puromycin, $0.5 \mu \mathrm{g} / \mathrm{ml}$ hygromycin and $1 \mu \mathrm{g} / \mathrm{ml}$ tetracycline. Clones were PCR-tested for correct integration using primer 5 UTR_control TCGTCCGCGCCTTTGTGTAGCTA, which binds 50 bp upstream of the $55^{\prime}$-recombination site, in combination with different reverse primers.

31 Construction of c-Myc-tagged proteins was done as described (Schädeli, et al., 32 2019). 
For Southern blot analysis, $1.5 \mu \mathrm{g}$ Nol or Pstl/Sphl-digested genomic DNA 2 was separated on a $1 \%$ agarose gel and transferred to hybond-N+ nylon transfer membrane (Amersham Pharmacia Biotech, Glattbrugg, Switzerland) using 10xSSC buffer (150 mM Na 3 -citrate, $\mathrm{pH} 7.0,1.5 \mathrm{M} \mathrm{NaCl}$ ) as described (Serricchio \& Bütikofer, 2012). The membrane was probed with a $400 \mathrm{bp}{ }^{32} \mathrm{P}$-labelled PCR product of the TbCls 3'UTR generated with the prime-a-gene labelling system (Promega). Primers used for PCR were: 3 'UTR_fwd CCCTCTAGACAGCTCACGAACCGTGCCCTA and 3'UTR_rev: CCCGCGGCCGCTATCCGTCGAGGGCCACCC. Hybridized probe was detected by autoradiography using BioMax MS films in combination with intensifying screens.

Metabolic labeling

Approximately $10^{7}$ parasites in mid-log phase were labelled with $10 \mu \mathrm{Ci}\left[{ }^{3} \mathrm{H}\right]-$ glycerol for $6 \mathrm{~h}$ followed by washing, lipid extraction, thin-layer chromatography and

Preparation of crude membrane fractions and membrane proteins

Crude mitochondrial preparations were obtained by digitonin extraction as described elsewhere (Charriere, Helgadottir, Horn, Soll, \& Schneider, 2006). Briefly, $10^{8}$ trypanosomes were washed in SBG buffer $(150 \mathrm{mM}$ Tris $\cdot \mathrm{HCl}, \mathrm{pH} 7.9,20 \mathrm{mM}$ glucose monohydrate, $20 \mathrm{mM} \mathrm{NaH} \mathrm{PO}_{4}$ ) and parasites collected by centrifugation (1500 x g, $5 \mathrm{~min})$. Cells were suspended in $0.5 \mathrm{ml}$ SoTE $(20 \mathrm{mM}$ Tris $\cdot \mathrm{HCl}, \mathrm{pH} 7.5$, $0.6 \mathrm{M}$ sorbitol, $0.2 \mathrm{mM}$ EDTA) followed by the addition of SoTE containing $0.05 \%$ (w/v) digitonin. After $5 \mathrm{~min}$ incubation on ice, non-lysed cells were removed by centrifugation for $5 \mathrm{~min}$ at $800 \times \mathrm{g}$ and crude membrane fraction was collected by another centrifugation step ( $\left.6000 \times \mathrm{g}, 5 \mathrm{~min}, 4^{\circ} \mathrm{C}\right)$. For complete membrane lysis and extraction of membrane proteins, the pellet was dissolved in $100 \mu$ lextraction buffer (20 mM Tris $\cdot \mathrm{HCl}, \mathrm{pH} 7.2,15 \mathrm{mM} \mathrm{NaH}_{2} \mathrm{PO}_{4}, 0.6 \mathrm{M}$ sorbitol) containing $1.5 \%(\mathrm{w} / \mathrm{v})$ digitonin and incubated on ice for $15 \mathrm{~min}$. Solubilized proteins were cleared from insoluble material by centrifugation $\left(16^{\prime} 000 \times \mathrm{g}, 30 \mathrm{~min}\right.$ at $\left.4^{\circ} \mathrm{C}\right)$ and used for further analysis. 
To immunoprecipitate TbCls-HA, crude membranes isolated from $5 \times 10^{8}$ 2 parasites were solubilized with $100 \mu$ I RIPA buffer (25 mM Tris- $\mathrm{HCl}, \mathrm{pH}$ 7.4, $150 \mathrm{mM}$

$3 \mathrm{NaCl}, 0.1 \%$ SDS, $0.5 \%$ sodium deoxycholate, $1 \% \mathrm{NP}-40$ ) and heated to $65{ }^{\circ} \mathrm{C}$ for 5 minutes. After dilution with $900 \mu \mathrm{IP}$ buffer (10 mM Tris-HCl, pH 7.4, $150 \mathrm{mM} \mathrm{NaCl}, 1$ mM EDTA, 1\% Triton X-100, 0.5\% NP-40, protease inhibitors) and centrifugation $\left(16^{\prime} 000 \times \mathrm{g}, 30 \mathrm{~min}\right.$ at $\left.4^{\circ} \mathrm{C}\right)$, anti-HA (16B12, Enzo Life Sciences) antibody was added in combination with Protein G Dynabeads (Thermo Fisher Scientific) and incubated for $16 \mathrm{~h}$. After washing with IP buffer, proteins were eluted by SDS sample buffer and analyzed by immunoblotting as described below.

\section{Polyacrylamide gel electrophoresis and immunoblotting}

Proteins were denatured by SDS and separated using $12 \%$ polyacrylamide gels under reducing conditions (SDS-PAGE). Alternatively, blue native polyacrylamide gel electrophoresis (BN-PAGE) was performed using digitonin extracts and separation by $4-12 \%$ acrylamide gradient gels at $4{ }^{\circ} \mathrm{C}$ (Wittig, Braun, \& Schagger, 2006). Subsequently, proteins were transferred onto nitrocellulose membranes (Thermo Scientific) or Immobilon-P polyvinylidene difluoride membranes (Millipore, Billerica, MA) using a semi-dry protein blotting system (BioRad, Cressier, Switzerland). After blocking the membrane in TBS (10 mM Tris $\cdot \mathrm{HCl} \mathrm{pH} 7.5,144 \mathrm{mM}$ $\mathrm{NaCl})$ containing $5 \%(\mathrm{w} / \mathrm{v})$ milk powder, membranes were exposed to primary antibodies mouse anti-Hsp70 (provided by André Schneider, University of Bern, Switzerland or (Panigrahi et al., 2008)), mouse anti-HA (HA.11, 16B12, Enzo Life Sciences, Lausen, Switzerland), rabbit anti-ATP synthase subunits $\beta, p 18$, ATPaseTb1, ATPaseTb2 and OSCP (Subrtova, et al., 2015), rabbit anti-AAC and anti-VDAC (Singha, Sharma, \& Chaudhuri, 2009), mouse anti-AOX (provided by Minu Chaudhuri, Chicago Medical School, Chicago, IL), diluted 1:1000-1:5000 in TBS containing 5\% (w/v) milk powder. Horseradish peroxidase-conjugated secondary anti-mouse and anti-rabbit antibodies (Dako, Glostrup, Denmark) were used at concentrations of $1: 5000$ and 1:1000, respectively, and detected using an enhanced chemiluminescence detection kit (Thermo Scientific). Protein sizes were determined using PageRuler Plus Prestained Protein Ladder (Thermo Scientific) and NativeMark ${ }^{\mathrm{TM}}$ Unstained Protein Standard (Invitrogen). For protein quantitation, total cell lysates from $4 \times 10^{6}$ cells were loaded on TGX stain-free precast gels (BioRad) and subjected to SDS-PAGE before transfer to polyvinylidene difluoride membranes. 
1 Subsequently, proteins were immunodetected by specific antibodies and visualized 2 using ChemiDoc ${ }^{\mathrm{TM}}$ Gel Imaging System. Signals from TbCls-depleted cells were compared to control samples and then normalized to Hsp70 loading control. The relative expression of the individual proteins was plotted using Graph Pad Prism 8.2.1.

\section{Transmission electron microscopy}

TbCls KO parasites were cultured in the presence or absence of tetracycline to maintain or induce, respectively, ablation of $\mathrm{TbCls}$ expression. Trypanosomes were washed in PBS ( $\mathrm{pH}$ 7.4, $137 \mathrm{mM} \mathrm{NaCl}, 2.7 \mathrm{mM} \mathrm{KCl}, 10 \mathrm{mM} \mathrm{Na} 2 \mathrm{HPO}_{4}, 1.8 \mathrm{mM}$ $\mathrm{KH}_{2} \mathrm{PO}_{4}$ ) and processed for TEM analysis as described elsewhere (Dawoody Nejad, Serricchio, Jelk, Hemphill, \& Bütikofer, 2018; Schädeli, et al., 2019).

Stable isotope labeling with amino acids in cell culture (SILAC)

SILAC and liquid chromatography-mass spectrometry/mass spectrometry was done as described before (Schädeli, et al., 2019).

MitoTracker staining

Live trypanosomes $\left(2 \times 10^{6}\right.$ cells) were stained in culture medium with $100 \mathrm{nM}$ MitoTracker Red $\mathrm{CM}-\mathrm{H}_{2}$ XRos (Invitrogen) for 30 min. After washing, parasites were resuspended in PBS, allowed to adhere to a microscope slide (Thermo Scientific) for $15 \mathrm{~min}$, fixed in PBS containing 4\% (w/v) paraformaldehyde for $10 \mathrm{~min}$, washed and air-dried before mounting with Vectashield (Vector Laboratories, Burlingame, CA) containing $1.5 \mu \mathrm{g} / \mathrm{ml}$ 4',6-diamidino-2-phenylindole (DAPI). The images were acquired using a Leica DMI6000 B microscope with 60x oil objective.

\section{Metabolomic analysis}

Metabolites were extracted from $10^{8}$ parasites by rapid cooling to $4{ }^{\circ} \mathrm{C}$ by submersion of the tube in a dry ice/ethanol bath. After centrifugation for 10 minutes at $1000 \times \mathrm{g}$, the supernatant was removed completely and the pellet suspended in 200 $\mu \mathrm{l}$ chloroform/methanol/water (1:3:1 ratio) at $4{ }^{\circ} \mathrm{C}$. After mixing with a pipette, samples were rocked for $1 \mathrm{~h}$ at $4{ }^{\circ} \mathrm{C}$, cleared at $13000 \times \mathrm{g}$ for $3 \mathrm{~min}$ and $180 \mu \mathrm{l}$ of the supernatant was transferred into a new tube and stored at $-80^{\circ} \mathrm{C}$ until analysis. 
Hydrophilic interaction liquid chromatography (HILIC) was carried out on a 2 Dionex UltiMate 3000 RSLC system (Thermo Fisher Scientific, Hemel Hempstead, 3 UK) using a ZIC-pHILIC column (150 mm × $4.6 \mathrm{~mm}, 5 \mu \mathrm{m}$ column, Merck Sequant). 4 The column was maintained at $30^{\circ} \mathrm{C}$ and samples were eluted with a linear gradient of solvent A (20 mM ammonium carbonate in water) in acetonitrile over $26 \mathrm{~min}$ at a flow rate of $0.3 \mathrm{ml} / \mathrm{min}$. For mass spectrometry (MS) analyses, a Thermo Orbitrap Fusion (Thermo Fisher Scientific) was operated in polarity switching mode and the MS settings were as follows: resolution 120'000; AGC 2e5; m/z range 70-1000; sheath gas 40; Auxiliary gas 5; sweep gas 1 ; probe temperature $150{ }^{\circ} \mathrm{C}$; capillary temperature $325{ }^{\circ} \mathrm{C}$. For positive mode ionization: source voltage $+4.3 \mathrm{kV}$. For negative mode ionization: source voltage $-3.2 \mathrm{kV}$. S-Lens RF level $30 \%$. Fragmentation was performed with the following parameters: collision energy: $60 \%$; stepped collision energy: 35\%; isolation window: 2; dynamic exclusion after 1 time; exclusion duration: 6 seconds; exclude isotopes: true; minimum intensity: 50,000. Instrument raw files were converted to positive and negative ionization mode $\mathrm{mzXML}$ files. These files were then analyzed using PiMP (Gloaguen, et al., 2017) in combination with FrAnK (an in-house fragmentation tool).

Mitochondrial membrane potential $(\Delta \psi m)$

In vivo $\Delta \psi \mathrm{m}$ was measured using the cell-permeant red-fluorescent dye TMRE (tetramethylrhodamine ethyl ester, Thermo Fisher Scientific). For each time point, an equal number of parasites $\left(3 \times 10^{6}\right)$ was harvested and resuspended in culture medium containing $60 \mathrm{nM}$ TMRE. Mitochondrial staining was carried out for 30 min under standard culture conditions $\left(37{ }^{\circ} \mathrm{C}\right.$ and $\left.5 \% \mathrm{CO}_{2}\right)$. Subsequently, trypanosomes were spun down at $1400 \times \mathrm{g}$ for $10 \mathrm{~min}$ at room temperature, resuspended in $1 \mathrm{ml}$ of $1 \times$ PBS (10 mM phosphate buffer, $130 \mathrm{mM} \mathrm{NaCl}, \mathrm{pH} 7.3$ ), and immediately analyzed by flow cytometry (BD FACS Canto II Instrument) using the PE filter. For each sample, 10'000 events were collected. Treatment with $20 \mu \mathrm{M}$ FCCP (carbonyl cyanide 4-(trifluoromethoxy) phenylhydrazone) was used as a control for mitochondrial membrane depolarization. Data were evaluated using BD FACS Diva (BD Company) software. The experiments were performed in triplicates.

In situ $\Delta \psi m$ of permeabilized cells was determined fluorometrically employing safranin $O$. For each time point, $2 \times 10^{7}$ parasites were harvested and washed once with ANT buffer $(8 \mathrm{mM} \mathrm{KCl}, 110 \mathrm{mM} \mathrm{K}$-gluconate, $10 \mathrm{mM} \mathrm{NaCl}, 10 \mathrm{mM}$ free-acid 
1 Hepes, $10 \mathrm{mM} \mathrm{K}_{2} \mathrm{HPO}_{4}, 0.015 \mathrm{mM}$ EGTA potassium salt, $10 \mathrm{mM}$ mannitol, $0.5 \mathrm{mg} / \mathrm{ml}$ 2 fatty acid-free bovine serum albumin, $1.5 \mathrm{mM} \mathrm{MgCl}_{2}, \mathrm{pH} 7.25$ ) (Chinopoulos et al., 3 2009). The cell pellet was resuspended in $200 \mu$ of ANT buffer containing $5 \mu \mathrm{M}$ safranin O, $40 \mu \mathrm{M}$ digitonin and 2 mM ATP (PanReac AppliChem), and subsequently transferred into a white flat-bottom 96-well microtiter plate. Fluorescence was recorded in a Tecan Infinite ${ }^{\circledR} 200$ PRO series plate reader using 496 and $586 \mathrm{~nm}$ excitation and emission wavelengths, respectively. The $\mathrm{F}_{0} \mathrm{~F}_{1}-\mathrm{ATP}$ synthase inhibitor oligomycin $(10 \mu \mathrm{g} / \mathrm{ml})$ and the uncoupler SF6847 (250 nM) (Enzo Life Sciences) were added where indicated. The experiments were performed in triplicates.

Oxygen flux analysis

The oxygen consumption rate was determined using the Oroboros Oxygraph-2K (Oroboros Instruments Corp., Innsbruck, Austria). For each time point, $2 \times 10^{7}$ parasites were harvested and washed once with Mir05 mitochondrial respiration medium (0.5 mM EGTA, $3 \mathrm{mM} \mathrm{MgCl}$, $60 \mathrm{mM}$ lactobionic acid, $20 \mathrm{mM}$ taurine, $10 \mathrm{mM} \mathrm{KH} \mathrm{PO}_{4}, 20 \mathrm{mM}$ Hepes, $110 \mathrm{mM}$ sucrose, $1 \mathrm{mg} / \mathrm{ml}$ fatty acid-free bovine serum albumin, $\mathrm{pH}$ 7.1). The pellet was resuspended in $2.1 \mathrm{ml}$ of Mir05 and transferred into the respiration chamber at $37^{\circ} \mathrm{C}$ under constant stirring. To trigger AOX-mediated respiration, $20 \mathrm{mM}$ DL-glycerol-3-phosphate was added. Once the maximal respiration rate was achieved, respiration was inhibited by addition of 250 $\mu M$ SHAM (salicylhydroxamic acid). The most stable portion of either the oxygen consumption rate slope or the oxygen concentration in the chamber slope was determined for each biological replicate after the addition of the substrate and the inhibitor. The values were plotted and analyzed statistically using GraphPad Prism 8.0 software.

\section{ATP measurements}

Both the ADP/ATP ratio and the total cellular ATP content were measured using a bioluminescence-based ADP/ATP assay kit (Sigma) following the manufacturer's protocol. In brief, $1 \times 10^{6}$ parasites per time point were harvested and washed once with PBS-G (1x PBS containing $6 \mathrm{mM}$ glucose). Cells were resuspended in $10 \mu \mathrm{l}$ of PBS-G and transferred into a white flat-bottom 96-well microtiter plate. Bioluminescence was recorded using an Orion II microplate luminometer (Titertek Berthold) and the ADP/ATP ratios were calculated according to 
1 the manufacturer's protocol. The ATP content (first fluorescence read of the assay) of 2 TbCls-depleted trypanosomes was expressed relative to control parasites using 3 GraphPad Prism 8.0 software.

4 5

6 Acknowledgements

The work was supported by grant no. 169355 from the Swiss National Science Foundation to P.B, and by Czech Science Foundation (18-17529S) and

9 ERD fund (CZ.02.1.01/0.0/0.0/16_019/0000759) to A.Z. We thank André Schneider 10 (University of Bern) and Minu Chaudhuri (Chicago Medical School) for antibodies and 11 Anant K. Menon (Weill Cornell Medical College New York) for advice. P.B. thanks A. 12 Niederer, M. Bütikofer and R. Plant for support.

\section{Conflict of interest}

The authors declare that they have no conflicts of interest with the contents of this article.

\section{Author contributions}

MS, DS, AZ and PB designed research; MS, CHY, DS, HBH, AH and JG performed research; MS, CHY, DS, AH, JG, AZ and PB analyzed data; MS, AZ and PB wrote the manuscript. All authors reviewed the manuscript. 


\section{References}

Acehan, D., Malhotra, A., Xu, Y., Ren, M., Stokes, D. L., \& Schlame, M. (2011). Cardiolipin affects the supramolecular organization of ATP synthase in mitochondria. Biophys J, 100(9), 2184-2192. doi: 10.1016/j.bpj.2011.03.031

Baker, N., Hamilton, G., Wilkes, J. M., Hutchinson, S., Barrett, M. P., \& Horn, D. (2015). Vacuolar ATPase depletion affects mitochondrial ATPase function, kinetoplast dependency, and drug sensitivity in trypanosomes. [Research Support, Non-U.S. Gov't]. Proceedings of the National Academy of Sciences of the United States of America, 112(29), 9112-9117. doi: 10.1073/pnas.1505411112

Bakker, B. M., Michels, P. A., Opperdoes, F. R., \& Westerhoff, H. V. (1997). Glycolysis in bloodstream form Trypanosoma brucei can be understood in terms of the kinetics of the glycolytic enzymes. [Research Support, Non-U.S. Gov't]. The Journal of biological chemistry, 272(6), 3207-3215. doi: 10.1074/jbc.272.6.3207

Beleznai, Z., \& Jancsik, V. (1989). Role of cardiolipin in the functioning of mitochondrial L-glycerol-3-phosphate dehydrogenase. [Comparative StudyResearch Support, Non-U.S. Gov't]. Biochemical and biophysical research communications, 159(1), 132-139. doi: 10.1016/0006291x(89)92414-5

Beltran-Heredia, E., Tsai, F. C., Salinas-Almaguer, S., Cao, F. J., Bassereau, P., \& Monroy, F. (2019). Membrane curvature induces cardiolipin sorting. [Research Support, U.S. Gov't, Non-P.H.S.Research Support, Non-U.S. Gov't]. Communications biology, 2, 225. doi: 10.1038/s42003-019-0471-x

Beyer, K., \& Klingenberg, M. (1985). ADP/ATP carrier protein from beef heart mitochondria has high amounts of tightly bound cardiolipin, as revealed by 31P nuclear magnetic resonance. [Research Support, Non-U.S. Gov't]. Biochemistry, 24(15), 3821-3826. doi: 10.1021/bi00336a001

Cade, W. T., Spencer, C. T., Reeds, D. N., Waggoner, A. D., O'Connor, R., Maisenbacher, M., . . . Peterson, L. R. (2013). Substrate metabolism during basal and hyperinsulinemic conditions in adolescents and young-adults with Barth syndrome. [Research Support, N.I.H., Extramural]. Journal of inherited metabolic disease, 36(1), 91-101. doi: 10.1007/s10545-012-9486-x

Charriere, F., Helgadottir, S., Horn, E. K., Soll, D., \& Schneider, A. (2006). Dual targeting of a single tRNA(Trp) requires two different tryptophanyl-tRNA synthetases in Trypanosoma brucei. [Research Support, N.I.H., ExtramuralResearch Support, Non-U.S. Gov't]. Proceedings of the National Academy of Sciences of the United States of America, 103(18), 6847-6852. doi: 10.1073/pnas.0602362103

Chinopoulos, C., Vajda, S., Csanady, L., Mandi, M., Mathe, K., \& Adam-Vizi, V. (2009). A novel kinetic assay of mitochondrial ATP-ADP exchange rate mediated by the ANT. [Research Support, Non-U.S. Gov't]. Biophysical journal, 96(6), 2490-2504. doi: 10.1016/j.bpj.2008.12.3915

Cirovic, O., \& Ochsenreiter, T. (2014). Whole proteome analysis of the protozoan parasite Trypanosoma brucei using stable isotope labeling by amino acids in cell culture and mass spectrometry. [Research Support, Non-U.S. Gov't]. Methods in molecular biology, 1188, 47-55. doi: 10.1007/978-1-4939-114244

Claypool, S. M. (2009). Cardiolipin, a critical determinant of mitochondrial carrier protein assembly and function. [Research Support, N.I.H., ExtramuralReview]. 
Biochimica et biophysica acta, 1788(10), 2059-2068. doi: 10.1016/j.bbamem.2009.04.020

Claypool, S. M., Oktay, Y., Boontheung, P., Loo, J. A., \& Koehler, C. M. (2008). Cardiolipin defines the interactome of the major ADP/ATP carrier protein of the mitochondrial inner membrane. J Cell Biol, 182(5), 937-950.

Creek, D. J., Nijagal, B., Kim, D. H., Rojas, F., Matthews, K. R., \& Barrett, M. P. (2013). Metabolomics guides rational development of a simplified cell culture medium for drug screening against Trypanosoma brucei. [Evaluation StudyResearch Support, Non-U.S. Gov't]. Antimicrobial agents and chemotherapy, 57(6), 2768-2779. doi: 10.1128/AAC.00044-13

Dawoody Nejad, L., Serricchio, M., Jelk, J., Hemphill, A., \& Bütikofer, P. (2018). TbLpn, a key enzyme in lipid droplet formation and phospholipid metabolism, is essential for mitochondrial integrity and growth of Trypanosoma brucei. Molecular microbiology. doi: 10.1111/mmi.13976

Dean, S., Gould, M. K., Dewar, C. E., \& Schnaufer, A. C. (2013). Single point mutations in ATP synthase compensate for mitochondrial genome loss in trypanosomes. [Research Support, N.I.H., ExtramuralResearch Support, NonU.S. Gov't]. Proceedings of the National Academy of Sciences of the United States of America, 110(36), 14741-14746. doi: 10.1073/pnas.1305404110

Duncan, A. L., Robinson, A. J., \& Walker, J. E. (2016). Cardiolipin binds selectively but transiently to conserved lysine residues in the rotor of metazoan ATP synthases. [Research Support, N.I.H., Extramural]. Proceedings of the National Academy of Sciences of the United States of America, 113(31), 8687-8692. doi: 10.1073/pnas.1608396113

Eble, K. S., Coleman, W. B., Hantgan, R. R., \& Cunningham, C. C. (1990). Tightly associated cardiolipin in the bovine heart mitochondrial ATP synthase as analyzed by 31P nuclear magnetic resonance spectroscopy. J Biol Chem, 265(32), 19434-19440.

Fiedorczuk, K., Letts, J. A., Degliesposti, G., Kaszuba, K., Skehel, M., \& Sazanov, L. A. (2016). Atomic structure of the entire mammalian mitochondrial complex I. Nature, 538(7625), 406-410. doi: 10.1038/nature19794

Figueira, T. R., Melo, D. R., Vercesi, A. E., \& Castilho, R. F. (2012). Safranine as a fluorescent probe for the evaluation of mitochondrial membrane potential in isolated organelles and permeabilized cells. [Research Support, Non-U.S. Gov't]. Methods in molecular biology, 810, 103-117. doi: 10.1007/978-161779-382-0_7

Friedman, J. R., Moūrier, A., Yamada, J., McCaffery, J. M., \& Nunnari, J. (2015). MICOS coordinates with respiratory complexes and lipids to establish mitochondrial inner membrane architecture. [Research Support, N.I.H., ExtramuralResearch Support, Non-U.S. Gov't]. eLife, 4. doi: 10.7554/eLife.07739

Gahura, O., Subrtova, K., Vachova, H., Panicucci, B., Fearnley, I. M., Harbour, M. E., . . Zíková, A. (2018). The F1 -ATPase from Trypanosoma brucei is elaborated by three copies of an additional p18-subunit. [Research Support, Non-U.S. Gov't]. The FEBS journal, 285(3), 614-628. doi: 10.1111/febs.14364 Gloaguen, Y., Morton, F., Daly, R., Gurden, R., Rogers, S., Wandy, J., . . Burgess, K. (2017). PiMP my metabolome: an integrated, web-based tool for LC-MS metabolomics data. Bioinformatics, 33(24), 4007-4009. doi: 10.1093/bioinformatics/btx499 
Hannaert, V., Bringaud, F., Opperdoes, F. R., \& Michels, P. A. (2003). Evolution of energy metabolism and its compartmentation in Kinetoplastida. Kinetoplastid Biol Dis, 2(1), 11.

Huang, G., Ulrich, P. N., Storey, M., Johnson, D., Tischer, J., Tovar, J. A., . . . Docampo, R. (2014). Proteomic analysis of the acidocalcisome, an organelle conserved from bacteria to human cells. [Research Support, N.I.H., Extramural]. PLoS pathogens, 10(12), e1004555. doi: 10.1371/journal.ppat.1004555

Intlekofer, A. M., Wang, B., Liu, H., Shah, H., Carmona-Fontaine, C., Rustenburg, A. S., ... Thompson, C. B. (2017). L-2-Hydroxyglutarate production arises from noncanonical enzyme function at acidic $\mathrm{pH}$. Nature chemical biology, 13(5), 494-500. doi: $10.1038 /$ nchembio. 2307

Jiang, F., Gu, Z., Granger, J. M., \& Greenberg, M. L. (1999). Cardiolipin synthase expression is essential for growth at elevated temperature and is regulated by factors affecting mitochondrial development. Mol Microbiol, 31(1), 373-379.

Jiang, F., Rizavi, H. S., \& Greenberg, M. L. (1997). Cardiolipin is not essential for the growth of Saccharomyces cerevisiae on fermentable or non-fermentable carbon sources. Mol Microbiol, 26(3), 481-491.

Johnston, K., Kim, D. H., Kerkhoven, E. J., Burchmore, R., Barrett, M. P., \& Achcar, F. (2019). Mapping the metabolism of five amino acids in bloodstream form Trypanosoma brucei using U-(13)C-labelled substrates and LC-MS. [Research Support, Non-U.S. Gov't]. Bioscience reports, 39(5). doi: 10.1042/BSR20181601

Joshi, A. S., Thompson, M. N., Fei, N., Huttemann, M., \& Greenberg, M. L. (2012). Cardiolipin and mitochondrial phosphatidylethanolamine have overlapping functions in mitochondrial fusion in Saccharomyces cerevisiae. [Research Support, N.I.H., ExtramuralResearch Support, Non-U.S. Gov't]. The Journal of biological chemistry, 287(21), 17589-17597. doi: 10.1074/jbc.M111.330167

Kadenbach, B., Mende, P., Kolbe, H. V., Stipani, I., \& Palmieri, F. (1982). The mitochondrial phosphate carrier has an essential requirement for cardiolipin. [Research Support, Non-U.S. Gov't]. FEBS letters, 139(1), 109-112. doi: 10.1016/0014-5793(82)80498-5

Kim, D. H., Achcar, F., Breitling, R., Burgess, K. E., \& Barrett, M. P. (2015). LC-MSbased absolute metabolite quantification: application to metabolic flux measurement in trypanosomes. Metabolomics : Official journal of the Metabolomic Society, 11(6), 1721-1732. doi: 10.1007/s11306-015-0827-2

Klingenberg, M. (2009). Cardiolipin and mitochondrial carriers. Biochim Biophys Acta, 1788(10), 2048-2058. doi: 10.1016/j.bbamem.2009.06.007

Kovarova, J., \& Barrett, M. P. (2016). The Pentose Phosphate Pathway in Parasitic Trypanosomatids. [ReviewResearch Support, Non-U.S. Gov't]. Trends in parasitology, 32(8), 622-634. doi: 10.1016/j.pt.2016.04.010

Lai, D. H., Hashimi, H., Lun, Z. R., Ayala, F. J., \& Lukes, J. (2008). Adaptations of Trypanosoma brucei to gradual loss of kinetoplast DNA: Trypanosoma equiperdum and Trypanosoma evansi are petite mutants of T. brucei. [Research Support, Non-U.S. Gov't]. Proceedings of the National Academy of Sciences of the United States of America, 105(6), 1999-2004. doi: 10.1073/pnas.0711799105

Lange, C., Nett, J. H., Trumpower, B. L., \& Hunte, C. (2001). Specific roles of proteinphospholipid interactions in the yeast cytochrome bc1 complex structure.

[Research Support, Non-U.S. Gov'tResearch Support, U.S. Gov't, P.H.S.]. The EMBO journal, 20(23), 6591-6600. doi: 10.1093/emboj/20.23.6591 
Li, Y., Lou, W., Raja, V., Denis, S., Yu, W., Schmidtke, M. W., . . Greenberg, M. L. (2019). Cardiolipin-induced activation of pyruvate dehydrogenase links mitochondrial lipid biosynthesis to TCA cycle function. [Research Support, N.I.H., ExtramuralResearch Support, Non-U.S. Gov't]. The Journal of biological chemistry, 294(30), 11568-11578. doi: 10.1074/jbc.RA119.009037

Mileykovskaya, E., \& Dowhan, W. (2000). Visualization of phospholipid domains in Escherichia coli by using the cardiolipin-specific fluorescent dye 10-N-nonyl acridine orange. [Research Support, U.S. Gov't, P.H.S.]. Journal of bacteriology, 182(4), 1172-1175. doi: 10.1128/jb.182.4.1172-1175.2000

Mileykovskaya, E., \& Dowhan, W. (2014). Cardiolipin-dependent formation of mitochondrial respiratory supercomplexes. [Research Support, N.I.H., ExtramuralResearch Support, Non-U.S. Gov'tReview]. Chemistry and physics of lipids, 179, 42-48. doi: 10.1016/j.chemphyslip.2013.10.012

Muhleip, A., McComas, S. E., \& Amunts, A. (2019). Structure of a mitochondrial ATP synthase with bound native cardiolipin. [Research Support, Non-U.S. Gov't]. eLife, 8. doi: 10.7554/eLife.51179

Nishijima, S., Asami, Y., Uetake, N., Yamagoe, S., Ohta, A., \& Shibuya, I. (1988). Disruption of the Escherichia coli cls gene responsible for cardiolipin synthesis. J Bacteriol, 170(2), 775-780.

Nolan, D. P., \& Voorheis, H. P. (1992). The mitochondrion in bloodstream forms of Trypanosoma brucei is energized by the electrogenic pumping of protons catalysed by the $\mathrm{F}_{1} \mathrm{~F}_{0}-\mathrm{ATPase}$. [Research Support, Non-U.S. Gov't]. European journal of biochemistry, 209(1), 207-216. doi: 10.1111/j.14321033.1992.tb17278.x

Opperdoes, F. R., Borst, P., Bakker, S., \& Leene, W. (1977). Localization of glycerol3-phosphate oxidase in the mitochondrion and particulate NAD+-linked glycerol-3-phosphate dehydrogenase in the microbodies of the bloodstream form to Trypanosoma brucei. European journal of biochemistry, 76(1), 29-39. doi: 10.1111/j.1432-1033.1977.tb11567.x

Panigrahi, A. K., Zikova, A., Dalley, R. A., Acestor, N., Ogata, Y., Anupama, A., . . Stuart, K. D. (2008). Mitochondrial complexes in Trypanosoma brucei: a novel complex and a unique oxidoreductase complex. Molecular \& cellular proteomics : MCP, 7(3), 534-545. doi: 10.1074/mcp.M700430-MCP200

Paradies, G., Ruggiero, F. M., Petrosillo, G., \& Quagliariello, E. (1997). Alterations in carnitine-acylcarnitine translocase activity and in phospholipid composition in heart mitochondria from hypothyroid rats. [Research Support, Non-U.S. Gov't]. Biochimica et biophysica acta, 1362(2-3), 193-200. doi: 10.1016/s09254439(97)00075-6

Patil, V. A., Fox, J. L., Gohil, V. M., Winge, D. R., \& Greenberg, M. L. (2013). Loss of cardiolipin leads to perturbation of mitochondrial and cellular iron homeostasis. [Research Support, N.I.H., ExtramuralResearch Support, Non-U.S. Gov't]. The Journal of biological chemistry, 288(3), 1696-1705. doi:

10.1074/jbc.M112.428938

Pereira, C. A., Alonso, G. D., Torres, H. N., \& Flawia, M. M. (2002). Arginine kinase: a common feature for management of energy reserves in African and American flagellated trypanosomatids. [Comparative StudyResearch Support, Non-U.S. Gov't]. The Journal of eukaryotic microbiology, 49(1), 82-85. doi: 10.1111/j.1550-7408.2002.tb00346.x

Pineau, B., Bourge, M., Marion, J., Mauve, C., Gilard, F., Maneta-Peyret, L., . . . Danon, A. (2013). The importance of cardiolipin synthase for mitochondrial ultrastructure, respiratory function, plant development, and stress responses in 
Arabidopsis. [Research Support, Non-U.S. Gov't]. The Plant cell, 25(10), 4195-4208. doi: 10.1105/tpc.113.118018

Priest, J. W., \& Hajduk, S. L. (1994). Developmental regulation of mitochondrial biogenesis in Trypanosoma brucei. [Research Support, Non-U.S. Gov't

Research Support, U.S. Gov't, P.H.S.Review]. Journal of bioenergetics and biomembranes, 26(2), 179-191. doi: 10.1007/bf00763067

Raemy, E., Montessuit, S., Pierredon, S., van Kampen, A. H., Vaz, F. M., \& Martinou, J. C. (2016). Cardiolipin or MTCH2 can serve as tBID receptors during apoptosis. Cell death and differentiation, 23(7), 1165-1174. doi: 10.1038/cdd.2015.166

Raja, V., \& Greenberg, M. L. (2014). The functions of cardiolipin in cellular metabolism-potential modifiers of the Barth syndrome phenotype. [Research Support, N.I.H., ExtramuralResearch Support, Non-U.S. Gov'tReview]. Chemistry and physics of lipids, 179, 49-56. doi: 10.1016/j.chemphyslip.2013.12.009

Raja, V., Salsaa, M., Joshi, A. S., Li, Y., van Roermund, C. W. T., Saadat, N., . . Greenberg, M. L. (2019). Cardiolipin-deficient cells depend on anaplerotic pathways to ameliorate defective TCA cycle function. [Research Support, N.I.H., Extramural]. Biochimica et biophysica acta. Molecular and cell biology of lipids, 1864(5), 654-661. doi: 10.1016/j.bbalip.2019.02.001

Renner, L. D., \& Weibel, D. B. (2011). Cardiolipin microdomains localize to negatively curved regions of Escherichia coli membranes. [Research Support, Non-U.S. Gov'tResearch Support, U.S. Gov't, Non-P.H.S.]. Proceedings of the National Academy of Sciences of the United States of America, 108(15), 6264-6269. doi: 10.1073/pnas.1015757108

Santucci, R., Sinibaldi, F., Cozza, P., Polticelli, F., \& Fiorucci, L. (2019). Cytochrome c: An extreme multifunctional protein with a key role in cell fate. [Review]. International journal of biological macromolecules, 136, 1237-1246. doi: 10.1016/j.ijbiomac.2019.06.180

Schädeli, D., Serricchio, M., Ben Hamidane, H., Loffreda, A., Hemphill, A., Beneke, T., . . . Bütikofer, P. (2019). Cardiolipin depletion-induced changes in the Trypanosoma brucei proteome. FASEB journal : official publication of the Federation of American Societies for Experimental Biology, fj201901184RR. doi: 10.1096/fj.201901184RR

Schlame, M. (2008). Cardiolipin synthesis for the assembly of bacterial and mitochondrial membranes. J Lipid Res, 49(8), 1607-1620. doi: 10.1194/jIr.R700018-JLR200

Schlame, M., \& Ren, M. (2006). Barth syndrome, a human disorder of cardiolipin metabolism. FEBS Lett, 580(23), 5450-5455. doi: 10.1016/j.febslet.2006.07.022

Schlame, M., \& Ren, M. (2009). The role of cardiolipin in the structural organization of mitochondrial membranes. Biochim Biophys Acta, 1788(10), 2080-2083. doi: 10.1016/j.bbamem.2009.04.019

Schnaufer, A., Clark-Walker, G. D., Steinberg, A. G., \& Stuart, K. (2005). The F1ATP synthase complex in bloodstream stage trypanosomes has an unusual and essential function. [Research Support, N.I.H., ExtramuralResearch Support, Non-U.S. Gov't]. The EMBO journal, 24(23), 4029-4040. doi: 10.1038/sj.emboj.7600862

Schnaufer, A., Domingo, G. J., \& Stuart, K. (2002). Natural and induced dyskinetoplastic trypanosomatids: how to live without mitochondrial DNA. [Research Support, Non-U.S. Gov'tResearch Support, U.S. Gov't, 
P.H.S.Review]. International journal for parasitology, 32(9), 1071-1084. doi: 10.1016/s0020-7519(02)00020-6

Serricchio, M., \& Bütikofer, P. (2012). An essential bacterial-type cardiolipin synthase mediates cardiolipin formation in a eukaryote. Proc Natl Acad Sci U S A, 109(16), E954-961. doi: 10.1073/pnas.1121528109

Serricchio, M., \& Bütikofer, P. (2013). Phosphatidylglycerophosphate synthase associates with a mitochondrial inner membrane complex and is essential for growth of Trypanosoma brucei. [Research Support, Non-U.S. Gov't]. Molecular Microbiology, 87(3), 569-579. doi: 10.1111/mmi.12116

Shah, T. D., Hickey, M. C., Capasso, K. E., \& Palenchar, J. B. (2011). The characterization of a unique Trypanosoma brucei beta-hydroxybutyrate dehydrogenase. [Research Support, Non-U.S. Gov't]. Molecular and biochemical parasitology, 179(2), 100-106. doi: 10.1016/j.molbiopara.2011.07.001

Shiba, T., Kido, Y., Sakamoto, K., Inaoka, D. K., Tsuge, C., Tatsumi, R., . . Kita, K. (2013). Structure of the trypanosome cyanide-insensitive alternative oxidase. [Research Support, Non-U.S. Gov't]. Proceedings of the National Academy of Sciences of the United States of America, 110(12), 4580-4585. doi: 10.1073/pnas. 1218386110

Shinzawa-Itoh, K., Aoyama, H., Muramoto, K., Terada, H., Kurauchi, T., Tadehara, Y., ... Yoshikawa, S. (2007). Structures and physiological roles of 13 integral lipids of bovine heart cytochrome c oxidase. [Comparative StudyResearch Support, Non-U.S. Gov't]. The EMBO journal, 26(6), 1713-1725. doi: 10.1038/sj.emboj.7601618

Singha, U. K., Sharma, S., \& Chaudhuri, M. (2009). Downregulation of mitochondrial porin inhibits cell growth and alters respiratory phenotype in Trypanosoma brucei. [Research Support, N.I.H., Extramural]. Eukaryotic cell, 8(9), 14181428. doi: 10.1128/EC.00132-09

Smith, T. K., Bringaud, F., Nolan, D. P., \& Figueiredo, L. M. (2017). Metabolic reprogramming during the Trypanosoma brucei life cycle. [Review]. F1000Research, 6. doi: 10.12688/f1000research.10342.2

Solmaz, S. R., \& Hunte, C. (2008). Structure of complex III with bound cytochrome C in reduced state and definition of a minimal core interface for electron transfer. [Research Support, Non-U.S. Gov't]. The Journal of biological chemistry, 283(25), 17542-17549. doi: 10.1074/jbc.M710126200

Subrtova, K., Panicucci, B., \& Zíková, A. (2015). ATPaseTb2, a unique membranebound FoF1-ATPase component, is essential in bloodstream and dyskinetoplastic trypanosomes. [Research Support, Non-U.S. Gov't]. PLoS pathogens, 11(2), e1004660. doi: 10.1371/journal.ppat.1004660

Tielens, A. G., \& van Hellemond, J. J. (2009). Surprising variety in energy metabolism within Trypanosomatidae. [Review]. Trends in parasitology, 25(10), 482-490. doi: 10.1016/j.pt.2009.07.007

Uzcategui, N. L., Szallies, A., Pavlovic-Djuranovic, S., Palmada, M., Figarella, K., Boehmer, C., ... Duszenko, M. (2004). Cloning, heterologous expression, and characterization of three aquaglyceroporins from Trypanosoma brucei. [Research Support, Non-U.S. Gov't]. The Journal of biological chemistry, 279(41), 42669-42676. doi: 10.1074/jbc.M404518200

Vickerman, K. (1985). Developmental cycles and biology of pathogenic trypanosomes. Br Med Bull, 41(2), 105-114.

Voncken, F., Gao, F., Wadforth, C., Harley, M., \& Colasante, C. (2013). The phosphoarginine energy-buffering system of trypanosoma brucei involves 
multiple arginine kinase isoforms with different subcellular locations. PloS one, 8(6), e65908. doi: 10.1371/journal.pone.0065908

Wirtz, E., Leal, S., Ochatt, C., \& Cross, G. A. (1999). A tightly regulated inducible expression system for conditional gene knock-outs and dominant-negative genetics in Trypanosoma brucei. Mol Biochem Parasitol, 99(1), 89-101. doi: 10.1016/s0166-6851(99)00002-x

Wittig, I., Braun, H. P., \& Schagger, H. (2006). Blue native PAGE. [Research Support, Non-U.S. Gov't]. Nature protocols, 1(1), 418-428. doi: 10.1038/nprot.2006.62

Zíková, A., Hampl, V., Paris, Z., Tyc, J., \& Lukes, J. (2016). Aerobic mitochondria of parasitic protists: Diverse genomes and complex functions. [Review]. Molecular and biochemical parasitology, 209(1-2), 46-57. doi: 10.1016/j.molbiopara.2016.02.007

Zíková, A., Verner, Z., Nenarokova, A., Michels, P. A. M., \& Lukes, J. (2017). A paradigm shift: The mitoproteomes of procyclic and bloodstream Trypanosoma brucei are comparably complex. [Research Support, Non-U.S. Gov'tReview]. PLoS pathogens, 13(12), e1006679. doi: 10.1371/journal.ppat.1006679 